\title{
COVID19 Pandemic: How Effective Are Interventive Control Measures and Is A Complete Lockdown Justified? A Comparison of Countries and States
}

\section{Franz Konstantin Fuss ( $\sim$ fkfuss@swin.edu.au )}

Swinburne University https://orcid.org/0000-0001-9846-0985

\section{Yehuda Weizman}

Swinburne University of Technology - Hawthorn Campus: Swinburne University of Technology

Adin Ming Tan

Swinburne University of Technology - Hawthorn Campus: Swinburne University of Technology

\section{Research article}

Keywords: COVID-19, control measures, lockdown, effectiveness, effective phase, mortality, country maps, reproductive number

Posted Date: December 29th, 2020

DOl: https://doi.org/10.21203/rs.3.rs-132854/v1

License: (c) (i) This work is licensed under a Creative Commons Attribution 4.0 International License. Read Full License 


\section{COVID19 pandemic: how effective are interventive control measures and is a complete lockdown justified? A comparison of countries and states}

Franz Konstantin Fuss, Yehuda Weizman, Adin Ming Tan

Faculty of Health, Arts and Design, Swinburne University of Technology, Melbourne Australia

John Street, Hawthorn / Melbourne, VIC 3122, Australia

\section{Address for Correspondence}

Professor Franz Konstantin Fuss, MD, PhD

Email: fkfuss@swin.edu.au

Tel.: 61392146882

Faculty of Health, Arts and Design, Swinburne University of Technology, John Street, Hawthorn /

Melbourne, VIC 3122, Australia

\section{ABSTRACT \\ Background}

For fighting the COVID-19 pandemic, countries used control measures of different severity, from 'relaxed' to lockdown. Drastic lockdown measures are considered more effective, but also have a negative impact on the economy. When comparing the financial value of lost lives to the losses of an economic disaster, the better option seems to be lockdown measures.

\section{Methods}

We developed a new parameter, the effectiveness of control measures, calculated from the $2^{\text {nd }}$ time derivative of daily case data, and normalised to the average of the daily case data during the effective phase; and also calculated from the derivative of the logarithm of the reproductive number. We calculated this parameter and two associated parameters, i.e. effectiveness, duration of effective phase, and ratio of the 2 former parameters, for 92 countries, states and provinces, whose effective phase ended the latest on 15 May 2020. We compared these effectiveness parameters, and also the mortality during 
and after the effective phase, for countries with and without lockdown measures by means of the MannWhitney test.

\section{Results}

We did not find any statistically significant difference in the three effectiveness parameters, between countries with and without lockdown ( $\mathrm{p}>0.76$; very small effect size). There was also no significant difference in mortality during the effective phase ( $\mathrm{p}>0.1$; very small to small effect sizes), however a significant difference after the effective phase, with higher mortality for lockdown countries.

The effectiveness parameter derived from the daily case data correlated well with the parameter derived from the reproductive number $\left(\mathrm{R}^{2}=0.9480\right)$. The average duration of the effective phase was $17.3 \pm 10.5$ days.

\section{Conclusions}

The results indicate that lockdown measures are not necessarily superior to relaxed measures, which in turn are not necessarily a recipe for failure. Relaxed measures are, however, more economy-friendly. The higher mortality of lockdown countries is explained from the fact that, in our database, more lockdown countries than no-lockdown countries have higher mortality already during the effective phase that became significant only after the effective phase.

Key words: COVID-19; control measures; lockdown; effectiveness; effective phase; mortality; country maps; reproductive number

\section{BACKGROUND}

In December 2019, China detected a cluster of pneumonia cases in the city of Wuhan. In January 2020, this disease (COVID-19) was attributed to the discovery of a novel coronavirus, named SARS-CoV-2. Since then, COVID-19 spread rapidly to 120 countries [1] before the World Health Organization (WHO) declared a pandemic on 11 March 2020 [2]. In the media briefing on the same day, the WHO DirectorGeneral summed up the challenges and problems associated with controlling the pandemic [2]:

- $\quad$ Several countries have demonstrated that this virus can be suppressed and controlled.

- $\quad$ The challenge for many countries ... is not whether they can do the same - it's whether they will.

- $\quad$ We know that these measures are taking a heavy toll on societies and economies... 
All countries must strike a fine balance between protecting health, minimizing economic and social disruption, and respecting human rights.

This 'fine balance' was addressed by each country in different ways, by introducing various control measures. While many countries imposed nation-wide lockdowns, such as France, Italy, Spain, Austria, and Norway (just to name a few; Table 1), Sweden adopted a 'relaxed' approach, by 'largely using voluntary measures' [3]. Anders Tegnell, the current State Epidemiologist of Sweden, commented that 'Lockdown, closing borders - nothing has a historical scientific basis' [3].

Even though historical evidence for the effectiveness of lockdown measures seems to be missing, these measures were implemented for preventing a shortage of hospital beds and medical equipment (e.g. respirators), as well as for reducing the death toll.

Even more so, the 'fine balance' [2] between saving lives and saving the economy was debated [4]. Holden and Preston [4] compared the financial value lost to fatalities (assuming a fatality rate of $1 \%$ and using the Australian value of a statistical life), resulting in losses of A\$ 1.1 trillion, to the value lost from a lockdown, estimated at A 180 billion, and concluded that these dollar figures make 'the case for shutdown clear' and 'the shutdown wins'.

The nature of the COVID-19 pandemic offers the opportunity of comparing different countries in terms of the effectiveness of their control measures. Yet, how can we measure their effectiveness?

The problem was attempted qualitatively by using the decline of the instantaneous reproduction number $\left(R_{t}\right)$ [5-8] and the drop of the Infected Patient's Ratio [9].

The drawback of estimating $R_{t}$ hinges on the accuracy of the reported number of confirmed cases; and on accurate estimates of the serial interval distribution [10]. The reported number of confirmed cases is affected by various degrees of underreporting [11,12]. The average (or median) of the serial interval (in days) varies between different sources, from 3.95 [13] to 7.5 [14]. Moreover, $R_{t}$ is determined with different equations and methods [15-17], which do not necessarily deliver the same results [18].

Alfano and Ercolano [19] investigated the gradient of daily new cases versus cumulative cases across daily data from 202 countries and claimed, "that lockdown is effective in reducing the number of new cases in the countries that implement it, compared with those countries that do not". However, they did not provide any statistical evidence for their claim by means of data, specifically effectiveness data of the countries with and without lockdown, and p-values or effect sizes.

It is therefore paramount to find a method for calculating the effectiveness of control measures that is independent of the number of cases and unaffected by systematic errors.

The aim of this research is to develop, for the first time, a definition and a method for measuring the effectiveness of control measures of different countries as a new epidemiological parameter, as well as to provide, or refute, the evidence for lockdown measures being effective. 


\section{METHOD}

1) Rationale of the method

If the number of infected people grows naturally, exponentially or sub-exponentially [20], then the slope of the daily case numbers becomes steeper with time. If this development is interrupted by effective control measures, then the slope flattens. The more effective the measures, the quicker slope flattens, and eventually becomes negative, resulting in a deceleration and decline of the daily case numbers. The higher the daily case numbers, the steeper are their slopes. It is therefore evident that any effectiveness index should be independent of 'numbers' (daily case numbers in this context). Our proposed method, and the derivation of the effectiveness, hinges on normalising the time derivatives of daily case numbers such that the effectiveness is independent of scaling factors. If two countries share the same geometrical identity of daily cases that differ only by their scaling factors, then the effectiveness of their control measures is identical. The 'force' required for interrupting the natural growth and for bending the slope is supposed to be generated by control measures, at least in the early stages of an epidemic. As this 'force' is applied daily over a certain period, it is more appropriate to refer to the 'force rate' (force per unit time). It will be shown subsequently, that the outcome of this force rate is directly related to the effectiveness of control measures.

The term 'effectiveness' used in this study stems from the two different types of intervention studies, where "efficacy can be defined as the performance of an intervention under ideal and controlled circumstances, whereas effectiveness refers to its performance under 'real-world' conditions" [21,22].

2) Effectiveness parameters, mathematical derivation and terminology

Most commonly, confirmed cases are reported and visualised as cumulative cases, $C_{C}$, which approximately follow an $S$-shaped curve between 2 constant values, 0 and the maximum number of cases $\mathrm{C}_{\max }$.

The speed of the increase in cases, velocity $v$, corresponds to the daily case count (unit: cases per day, c/d). It has to be noted that the (numerical) integral of $v$ does not result in $C_{C}$, but rather in $C_{I}$, as $C_{C}$ is a summation. Thus, $C_{I}=\int_{t_{0}}^{t_{\max }} v \mathrm{~d} t \neq C_{C}$, where $t$ is the time in days. This implies that if $v$ is exponential, $C_{I}$ is exponential too, but $C_{C}$ is not. Note that $v$ is always positive.

The acceleration of the disease spreading, $a$, equals the (numerical) time derivative of $v$, namely $a=\mathrm{d} v / \mathrm{d} t$ (unit: $c / d^{2}$ ). The acceleration is positive or negative (= deceleration), if the velocity $v$ increases or decreases, respectively. 
In mechanical terms, the 'force' mentioned above equals the acceleration of an object times its mass; whereas the 'force rate', equals the jerk times the mass of the object.

The jerk (or jolt), $j$, of the spreading disease is the (numerical) time derivative of $a$, namely $j=\mathrm{d} a / \mathrm{d} t$. (unit: $\mathrm{c} / \mathrm{d}^{3}$ ). The jerk $j$ is positive or negative, if the acceleration increases or decreases, respectively. The major decrease of the acceleration (i.e. the major transition from acceleration to deceleration) is denoted by the effective phase or period, $T_{E}$ (measured in days). During $T_{E}, j$ is negative on average.

As will be shown later, the higher $C_{\max }$, the larger is the absolute jerk, $|j|$. This relationship prevents the direct comparison of the $j$-data of different countries. Therefore, for comparative reasons, $j$ has to be normalised to $v$. This normalisation process has 3 advantages:

- comparability across different $C_{\max }$;

- independence of the actual case numbers and their associated systematic errors (such as underreporting); and

- the definition of an effectiveness parameter, $E$, where $E=j / v\left(\right.$ unit: $\left.\mathrm{d}^{-2}\right)$.

a) Mathematical derivation of effectiveness parameters

A simple and suitable model for exemplifying and understanding the dynamics of the effectiveness $E$ is by applying a Gaussian function (bell curve) to the $v$-data:

$$
v=b \mathrm{e}^{-\frac{(t-m)^{2}}{s^{2}}}
$$

where $b$ is a multiplier (proportional to $C_{\max }$ ), $t$ is the time (in days), $m$ is the day where $v$ reaches its maximum and $s$ represents the width of the bell curve. The Gaussian function is symmetrical about $m$. Note that the standard structure of a Gaussian involves a multiplier of 2 in the denominator of the exponent, which is omitted here for simplification purposes.

Also, note that the Gaussian function is only one out of other suitable models and will by no means be used as a fit function applied to actual daily cases data. It simply serves to understand the dynamics and principles of effectiveness.

When simplifying Eqn (1) and setting $m$ to $0, t=0$ occurs at the velocity peak, and the time has a negative sign before the $v$-peak:

$$
v=b \mathrm{e}^{-\frac{t^{2}}{s^{2}}}
$$

The acceleration is then 
$a=-\frac{2 t}{s^{2}} b \mathrm{e}^{-\frac{t^{2}}{s^{2}}}$

and the jerk is

$$
j=\frac{4 t^{2}}{s^{2}} b \mathrm{e}^{-\frac{t^{2}}{s^{2}}}-\frac{2}{s^{2}} b \mathrm{e}^{-\frac{t^{2}}{s^{2}}}=\frac{b}{s^{2}} \mathrm{e}^{-\frac{t^{2}}{s^{2}}}\left(4 t^{2}-2\right)
$$

The two turning points (Figure 1), where the acceleration is at the maximum and starts to decrease, and the deceleration is at its minimum value starts to increase, are at $j=0$. The time of the two turning points, $t_{E 1}$ and $t_{E 2}$, marks the boundaries of the effective phase. As the bell curve is symmetrical, $t_{E 1}+t_{E 2}=0$, if $m=0$.

Equating Eqn (4) to zero and solving for $t$ yields

$$
t_{E}= \pm s \sqrt{0.5}
$$

Thus

$$
T_{E}=2 t_{E}=s \sqrt{2}
$$

The magnitude of acceleration and deceleration at $\pm t_{E}$ is

$$
a_{E}=\mp \frac{\sqrt{2} b \mathrm{e}^{-0.5}}{s}
$$

which also corresponds to the half impulse of the jerk $j$ over the effective phase.

For obtaining average jerk $\bar{j}_{E}$ over the half-impulse (same as average jerk $\bar{j}_{E}$ over the full-impulse $S_{j_{E}}$ ) of the effective phase, we have to divide $a_{E}$ by $t_{E}$.

$$
\bar{j}_{E}=\frac{a_{E}}{t_{E}}=\frac{2 a_{E}}{T_{E}}=-\frac{2 b \mathrm{e}^{-0.5}}{s^{2}}
$$

The peak jerk, $j_{\min }$, and peak velocity $v_{\max }$ occur at $t=0$. Setting $t$ to zero in Eqns (4) and (2) yields

$$
j_{\min }=-\frac{2 b}{s^{2}}
$$

and

$$
v_{\max }=b
$$

As can be seen from Eqns (2)-(4) and (7)-(10), all parameters are dependent on the number of cases, as these equations share the same multiplier $b$, which is identical to $v_{\max }$.

As such, to render these parameters independent of the number of cases, the parameters have to be normalised to $v_{\max }$, or to the average $v$ over the effective phase, $\bar{v}_{E}$. 
To calculate $\bar{v}_{E}$, we take the integral of $v$ from $t_{E 1}$ to $t_{E 2}$, and divide by $2 t_{E}$.

$\bar{v}_{E}=b \sqrt{\pi / 2} \operatorname{erf} \sqrt{0.5}$

where erf denotes the error function.

The Effectiveness is the mirrored jerk, normalised to the velocity. The smaller (more negative) the jerk is, the greater is the effectiveness. After normalisation of the jerk, we obtain the following effectiveness parameters, namely:

- the effectiveness $E$ in general

$E_{t}=-\frac{j_{t}}{v_{t}}=\frac{2-4 t^{2}}{s^{2}}$

- the peak effectiveness, $E_{\max }$,

$E_{\max }=-\frac{j_{\min }}{v_{\max }}=\frac{2}{s^{2}}$

- the average effectiveness, $\bar{E}$

$\bar{E}=-\frac{\bar{j}_{E}}{\bar{v}_{E}}=\frac{2 \mathrm{e}^{-0.5}}{s^{2} \sqrt{\pi / 2} \operatorname{erf} \sqrt{0.5}}$

Note that $\bar{E}$ defined as $-\bar{j}_{E} / \bar{v}_{E}$ is a weighted average, in contrast to an unweighted defined by the average of the ratio of $\bar{j}_{E}$ to $\bar{v}_{E}$. The weighting factor thereby is $v$, via $\bar{E}_{\text {weighted }}=\square(E \cdot v) / \square(v)=\square(j) / \square$ $(v)=\bar{j} / \bar{v}$ as per Eqn (14).

- ratio $\square$ of average effectiveness $\bar{E}$ to duration of effective phase $T_{E}$,

$\rho=\frac{\bar{E}}{T_{E}}=\frac{2 \mathrm{e}^{-0.5}}{s^{2} \sqrt{\pi / 2} \operatorname{erf} \sqrt{0.5}} / s \sqrt{2}=\frac{2 \mathrm{e}^{-0.5}}{s^{3} \sqrt{\pi} \operatorname{erf} \sqrt{0.5}}$

This ratio combines the opposite trends of $E$ and $T_{E}$ in a single parameter.

Eqns (12)-(15) are functions of $s$, but no longer functions of $b$, and thus independent of the case data. More precise, Eqns (12)-(15) are functions of $s^{-x}$ (where $x=1,2,3$ ), which indicates that the narrower (leptokurtic) the $v$-peak is, the more effective are the control measures. This applies to two cardinal parameters, namely $\bar{E}$ and $\square$. A third cardinal parameter, $T_{E}$, is a function of $s^{+1}$ according to Eqn (6) in a sense that the shorter the effective phase, the more effective are the control measures. 'Real-world' data are required for evaluating the three cardinal parameters, applied to daily case data (calculated from cumulative data) of different countries. 
Figure 1 shows all parameters, required for determining the effectiveness, in relation to each other, namely: $v, a, j, T_{E}, \bar{E}, S_{E}$, and $E_{\max }$.

b) Relationship between average effectiveness, $\bar{E}$, and the instantaneous effective reproduction number $R_{\text {eff }}$

For deriving Reff, we have to take the logarithm of the velocity $v$ and thus Eqn (2):

$$
\log (v)=\log (b)-\frac{t^{2}}{s^{2}}
$$

where log denotes the natural logarithm. The time derivative of this function is the logarithmic growth rate $K$

$$
K=\frac{\mathrm{d}(\log v)}{\mathrm{d} t}=-\frac{2}{s^{2}} t
$$

Note that the multiplier $b$ drops out which makes the gradient independent of the actual number of daily cases, as already seen in Eqns (12)-(14). This fact proves that $R$ can be very well calculated from underestimated data, which stands in contrast to the criticism by Leung at al. [10].

By using the exponential method of Diekmann et al. [17], $R_{\text {eff }}$ is finally calculated from

$$
R_{e f f}=\mathrm{e}^{-K S I}=\mathrm{e}^{-\frac{2}{s^{2}} t S I}
$$

where SI is the serial interval.

As $0 \leq R_{\text {eff }}<<\infty$, and as the transition from epidemic to endemic occurs at $R_{\text {eff }}=1$, taking the logarithm of Eqn (18) puts this transition at $\log \left(R_{\text {eff }}\right)=0$ :

$$
\log \left(R_{e f f}\right)=K S I=-\frac{2}{s^{2}} t S I
$$

The time derivative of this function is

$$
\frac{\mathrm{d}\left(\log R_{e f f}\right)}{\mathrm{d} t}=-\frac{2}{s^{2}} S I
$$

which is, expectedly, a constant, since Eqn (19) is linear and independent of $t$. This means that, in a Gaussian function model, the rate of $\log \left(R_{e f f}\right)$ decreasing with time is constant. However, Eqn (20) is dependent of $s^{2}$. The larger the value of $s$, the wider is the Gaussian curve, and the smaller is this gradient in Eqn (20). This principle establishes the relationship between $R$ eff, or more precisely the derivative of $\log \left(R_{\text {eff }}\right)$, with the effectiveness $E$ of preventive control measures, which is also a function of $s^{-2}$, 
according to Eqn (14). Thus, the steeper the gradient of $\log \left(R_{\text {eff }}\right)$, i.e. $-2 S I s^{-2}$, the more effective are the control measures.

Normalising Eqn (20) to SI, if the average or median SI is a COVID-19 associated constant, delivers the effectiveness calculated from $R$, denoted $E_{R}$

$$
E_{R}=\frac{\mathrm{d}\left(\log R_{e f f}\right)}{\mathrm{d} t} / S I=-\frac{2}{s^{2}}
$$

From Eqns (14) and (21),

$$
E_{R}=\bar{E}(\sqrt{0.5 \pi})(\operatorname{erf} \sqrt{0.5})\left(\mathrm{e}^{0.5}\right)=\bar{E} \sqrt{1.99}=1.41 \bar{E}
$$

This constant applies to Gaussian models only.

\section{Data processing of real-world data}

The processing procedure started with daily cumulative case data, $C_{C}$, commonly reported on websites as further specified below. The daily case data, $v$, were determined from $\square C_{C}$. Due to the noisy nature of the original $v$-data, they were pre-filtered and subjected to a double running average filter $\left(1^{\text {st }}\right.$ order Savitzky-Golay filter) with a window width of 3 data. The major data fit for identifying the trend was performed with a running quadratic filter ( $2^{\text {nd }}$ order Savitzky-Golay filter) over a window of 13 data. The filter method, specifically the window width of 13 data was obtained from a convergence test. In principle, the absolute peak data ( $\min$ and $\max$ ) of $a$ and $j$ become smaller, and may finally asymptote, as the window with widens (e.g. from 5 to 23 data). At smaller windows, the magnitude of the peak data is greater for two reasons: the slope of the filter data is steeper, and the local noise (data fluctuations) is more pronounced. Consequently, the data fluctuations were assessed by means of a randomness index RI (RI-p-ap method [23]; 0 = perfectly correlated, 0.5 = perfectly random; 1 = perfectly anticorrelated). The smaller RI, the less the data fluctuate. The RI-data of $a$ and $j$ asymptoted at an average window width of 13 (11-15). Using the quadratic filter without the preceding double average filters would require a wider window than 13 data to achieve the same RI effect, but resulted in smaller peak data.

The resulting dataset of filtered $v$-data served for two purposes:

- Each filtered v-datum corresponds to the midpoint of a quadratic fit curve over 13 pre-filtered v-data. The residuals between filtered $v$-data and original $v$-data were used to calculate the confidence interval of each filtered $v$-datum. The residual standard deviation of each filtered $v$-datum was divided by $\sqrt{ } 13$ to obtain the standard error, which was multiplied by the $\mathrm{t}$-distribution of degrees of freedom $=$ 10 and $\square=0.05$ to obtain the $95 \%$ confidence for each filtered $v$-datum. 
- The filtered $v$-data including their $95 \%$ confidence interval data were numerically differentiated twice by calculating the slope over 3 data points to obtain $a$ and $j$.

Finally, $E$ was computed from $-j / v$.

The effective phase $T_{E}$ was defined as the time between an $a_{\max }$ and an $a_{\min }$, where $a_{\max }$ was positive and $a_{\min }$ was negative, and

$\square a=a_{\max }-a_{\min }$

where $\square a$ was the greatest of the entire dataset. $a_{\max }$ and $a_{\min }$ were determined visually, according to the aforementioned guidelines.

The impulse of the jerk over the effective phase was

$S_{j}=\square a$

The duration of the effective phase, $T_{E}$, was determined from its boundaries $t_{E 1}$ and $t_{E 2}$ where $t_{E}$ corresponded to the intersections of the $j$-data and the zero line (intersection of a straight line between 2 consecutive data points, one positive and one negative), one intersection at $a_{\max }$ and one at $a_{\min }$. Note that $T_{E}$ is usually non-integer.

$T_{E}=\square \mathrm{t}=t_{E 2}-t_{E 1}$

$\bar{j}_{E}=\square a / T_{E}$

$\bar{v}_{E}$.was calculated from averaging the $v$-data over $T_{E}$.

$\bar{E}=\bar{j}_{E} / \bar{v}_{E}$

The parameters obtained from Eqns (23) - (27) were determined from the filtered $v$-data and their confidence bounds (lower and upper). Note that after differentiating $v$ with time, once and twice, the resulting confidence bounds for the parameters obtained from Eqns (23) - (27) are not necessarily lower and upper anymore, as their value depends on the instantaneous slope of the $v$-curve, and of the $a$-curve.

The profile or shape of the velocity curve was assessed theoretically and practically. It is evident that real-life velocity data (daily cases data) do not necessarily follow a Gaussian function.

When modifying Eqn (2) to

$v=b \mathrm{e}^{-\frac{|t|^{h}}{s^{2}}}$

where $h$ modifies the shape, then we obtain a Gaussian function if $h=2$. If $h \rightarrow 1$, the function becomes more triangular. If $h>2$, then the curve becomes more trapezoidal and finally rectangular at $h>>2$; both shapes are characterised by a distinct plateau. The $v$-data simulated from Eqn (28) served for classifying $T_{E}$ and $\bar{E}$ data in relation to the Gaussian function $(h=2)$. 
Practically, the different shapes were determined from the deviation from the initial theoretical Eqn (2) where all $T_{E}$ and $\bar{E}$ data follow a Gaussian function. As such, the $s$-parameter was determined for $T_{E}$ and $\bar{E}$ from both Eqns (5) and (14), respectively:

$s_{T}=\frac{T_{E}}{\sqrt{2}}$

$s_{E}=\sqrt{\frac{2 \mathrm{e}^{-0.5}}{\bar{E} \sqrt{\pi / 2} \operatorname{erf} \sqrt{0.5}}}$

If the $T_{E}$ and $\bar{E}$ data follow a Gaussian function, then $S_{E}=S T$, and the ratio $\square=S E / S T$ must be unity.

$\varsigma=\frac{s_{E}}{s_{T}}=\sqrt{\frac{1}{T_{E}^{2} \bar{E}}} \sqrt{\frac{4 \mathrm{e}^{-0.5}}{\sqrt{\pi / 2} \operatorname{erf} \sqrt{0.5}}}$

The ratio $\square$ when expressed as $\log \square$, determines the shape of the velocity profile, where $\log \square>0$ is more triangular shaped, $\log \square<0$ is more trapezoidal-shaped, and $\log \square=0$ is bell-shaped (Gaussian function).

For constructing an isoline with a fixed $\square$-value, and calculating it from $\bar{E}$ as a function of $T_{E}$

$$
\bar{E}=T_{E}^{-2} \varsigma^{-2}\left(\frac{4 \mathrm{e}^{-0.5}}{\sqrt{\pi / 2} \operatorname{erf} \sqrt{0.5}}\right)
$$

The principle of average effectiveness $\bar{E}$, and the effective phase $T_{E}$ is shown in Figure 1, calculated from simulated daily case numbers (velocity $v$ ), and their consecutive time derivatives, acceleration $a$ and jerk $j$.

The average effectiveness derived from $R_{\text {eff }}$, i.e. $\bar{E}_{R}$, was calculated from

$$
\bar{E}_{R}=-\frac{\Delta \log R_{e f f}}{T_{E}} / S I
$$

where $\square \log R_{\text {eff }}$ denotes the decrease of $\log R_{\text {eff }}$ during the effective phase.

$\bar{E}_{R}$ was correlated to $\bar{E}$ and to the shape factor $\log \square$. From the three values of the coefficient of determination $\left(\mathrm{R}^{2}\right)$ of multiple and single regressions, the combined influence was calculated from the sum of the $\mathrm{R}^{2}$ of the single regressions minus the $\mathrm{R}^{2}$ of the multiple regression. The individual influences (semi-partial correlations) of $\bar{E}$ and $\log \square$ were calculated from the single regression $\mathrm{R}^{2}$ minus the combined influence. The influences were expressed as a percentage, resulting from $100 * \mathrm{R}^{2}$.

This correlation exercise served to prove practically that $\bar{E}_{R}$ is directly related to $\bar{E}$, a proof that was already established theoretically in Eqn (22) for a Gaussian v-profile; and for cross-validating the two 
different methods. The drawback of the $2^{\text {nd }}$ method, however, namely calculating the effectiveness $\left(\bar{E}_{R}\right)$ from $R_{\text {eff, }}$ is that the start and end of the effective phase has to be predetermined from the first method, which is the positive and negative peak data of the acceleration $a$ (Figure 1). Taking the steepest gradient of $\log \left(R_{\text {eff }}\right)$, or the gradient at $R_{\text {eff }}=1$, provides only a local maximum or value, respectively, of $E_{R}$, instead of an average $\bar{E}_{R}$ across the effective phase.

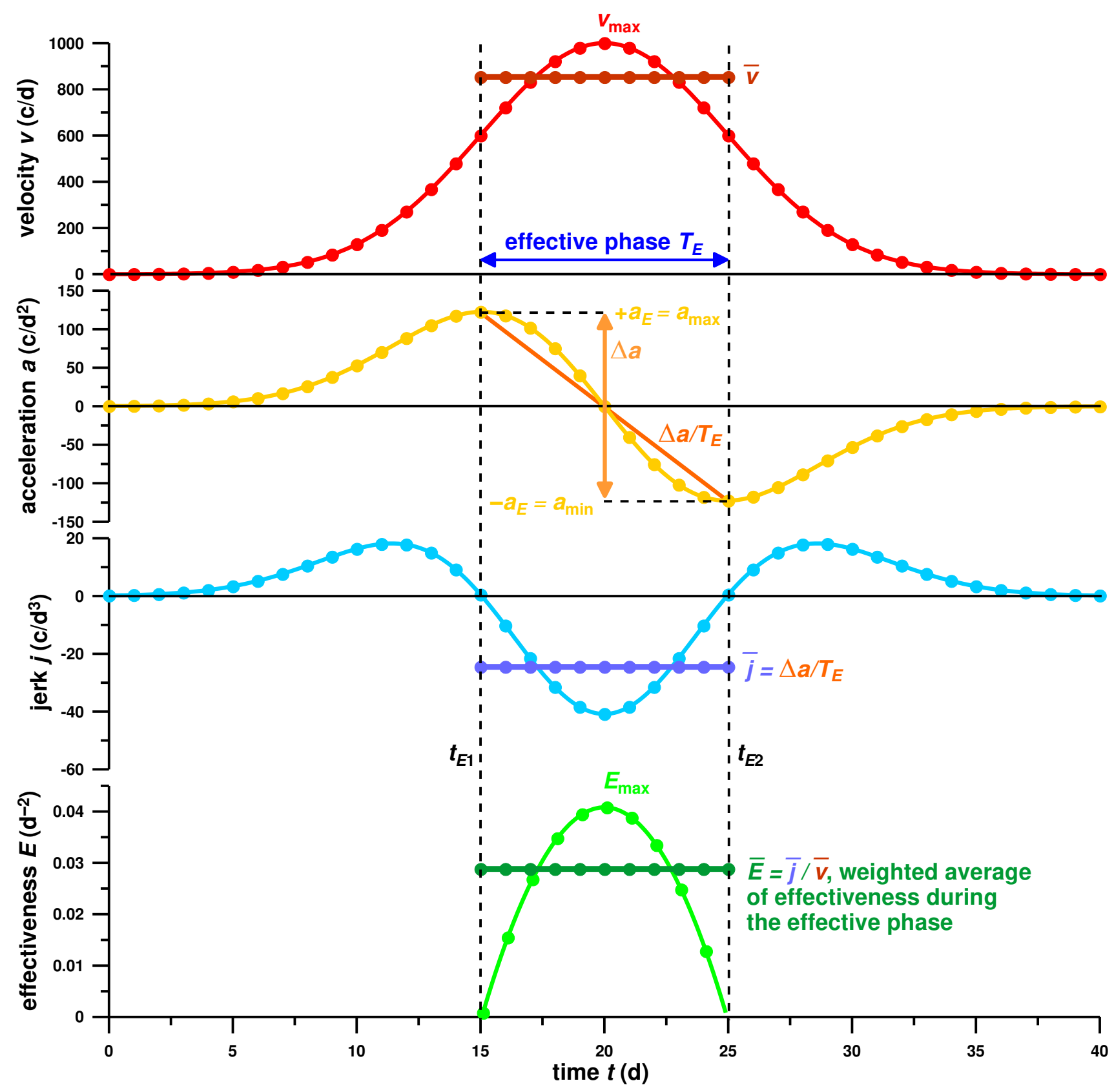

Figure 1: Explanation of the derivation of effectiveness parameters; daily case data (velocity $v$; following a hypothetical Gaussian function of $\left.v=1000 \exp \left[-(t-20)^{2} / 7^{2}\right]\right)$ against time $t(\bar{v}=$ average velocity of the effective phase $T_{E} ; v_{\max }=$ peak velocity $)$; acceleration $a$, first time derivative of the daily case data $\left(a_{\max }=+a_{E}=\right.$ maximum acceleration; $a_{\min }=-a_{E}=$ minimum; $\square a=a_{\max }-a_{\min } ; \square a / T_{E}=$ acceleration gradient across the effective phase); jerk $j$, second time derivative of the daily case data ( $\bar{j}=$ average jerk of the effective phase); and effectiveness $E$ 
of control measures against time ( $\bar{E}=$ average effectiveness of the effective phase); $t_{E 1,2}=$ start and end of effective phase.

\section{3) Data sets of real-world data}

We collected publicly available data of cumulative and daily cases [1] reported for the countries, states and provinces listed in Table 1 . We analysed the daily case data, calculated from the cumulative data, of 92 countries, states and provinces using the method described above. The countries, states and provinces were selected based on the following inclusion criteria: $T_{E}$ ending the latest on 15 May 2020, and $C_{C} \geq$ 250 at this date. We took the cumulative case data and cumulative death data from several websites that provide databases for different countries, states and provinces ${ }^{\mathbf{1}}$.

\section{4) Classification of intervention measures}

There are already some webpages [24] available, that provide (at least partially) information on lockdowns and restrictions related to the COVID-19 pandemic. We used this information and associated references found on these webpages for assigning countries, states and provinces to 2 groups - lockdown, and no lockdown - according to the definition below, and to our best of our knowledge, belief and understanding, when compiling all the information found on the internet. We excluded the following countries from this classification: Russia, as there was not a nationwide lockdown but only in some cities and regions; USA, which was treated by states; and China, with was treated by provinces.

Defining a 'lockdown' for decision making is a subjective process, more exclusive rather than inclusive, mostly by judging what it is not.

For this study, we define a lockdown as

a) a nationwide (state-wide / territory-wide) compulsory stay-home order for 24 hours per day and at least for 14 days,

b) enforced by law, police and by penalties in case of infringement,

c) with very few exceptions that allow people to leave their home (e.g. essential work and study, shopping for essential goods, medical care, exercise, etc.).

It is evident that this compulsory stay-home order further, but not necessarily, implies: the closure of schools and universities, non-essential businesses, and places for public gathering such as restaurants and entertainment facilities; prohibition of visiting of friends and relatives (indoor gatherings) and outdoor gatherings; abiding social distancing rules and mask orders; etc.

What a 'lockdown', by our definition, is not, infer: any of the implications, single or combined, that arise from a compulsory stay home order, in absence of the cardinal compulsory stay home order; voluntary 
stay-home orders, where people are advised or directed to stay home (e.g. Florida; people 'shall stay home' or 'shall limit their movements' [25] instead of must); age-dependent compulsory stay-home orders (e.g. elderly citizens); curfews for less than 24 hours such as during night time (e.g. Serbia); compulsory stay-home orders of less than 14 days (e.g. Israel); movement control orders (e.g. Malaysia); fines for breaching the physical distancing rule, in absence of a compulsory lockdown (e.g. Netherlands).

\section{5) Statistics}

From the daily case data, the following parameters were calculated, by using the method described above: $v$ (filtered), $a, j, T_{E}, \bar{E}, \square$, and $\square$. Except for $\square$ and $\square$, for all other parameters the upper and lower confidence interval bounds were determined.

As $T_{E}, \bar{E}, \square$, data were not normally distributed, we used the Mann-Whitney test for comparing these parameters for countries with and without lockdown. The threshold for a significant difference was $\square=$ 0.05. The effect size $r$ was calculated from the smaller $\mathrm{U}: r=1-2 \mathrm{U} /\left(\mathrm{n}_{1} \cdot \mathrm{n}_{2}\right)$, where $\mathrm{n}_{1}$ and $\mathrm{n}_{2}$ are the numbers of data of each of the 2 groups. The effect sizes $r$ were interpreted according to McGrath and Meyer, 2006 [26].

The mortality was determined from the number of deaths in a population normalised to the size of the population of countries/states/provinces listed in Table 1 at a specific point in time during the COVID-19 pandemic (data at the beginning, middle and end of the effective phase; and as of 26/06/2020). We compared the mortality of countries with and without lockdown with the Mann-Whitney test.

The effectiveness was visualised in Matlab (Release 2018b, The MathWorks, Inc., Natick, Massachusetts, United States) for European countries by colour-coding the parameters $T_{E}, \bar{E}, \square$, and $\square$.

Table 1. Countries and effectiveness parameters for countries, states and provinces whose effective phase ended the latest on 15 May 2020; LOCK: lockdown measures ( $\mathrm{Y}=$ yes, $\mathrm{N}=$ no; $\mathrm{X}$ : lockdown only in some cities, or country replaced by individual states or provinces [USA and CHN]); $T_{E}=$ effective phase; $\mathrm{CI}=95 \%$ confidence interval; $E=$ effectiveness; $\square=E / T_{E} ; \square=$ shape parameter of velocity profile); 3-letter country codes according to ISO 3166-1 Alpha-3; Chinese provinces 2-letter codes: ISO 3166-2:CN; 2-letter code of the states of the USA: ISO 3166-2:US; KOS = Kosovo; $R_{\text {eff }}=$ effective reproduction number.

\begin{tabular}{|c|c|c|c|c|c|c|c|c|c|c|c|}
\hline Country & ISO code & LOCK & $\boldsymbol{T}_{E}(\mathrm{~d})$ & $\begin{array}{l}T_{E} \text {, lower } \\
\text { CI }\end{array}$ & $\begin{array}{l}T_{E}, \\
\text { upper CI }\end{array}$ & $\begin{array}{l}\text { average } \\
\boldsymbol{E}\left(10^{-3} \mathrm{~d}^{-}\right. \\
\left.{ }^{2}\right)\end{array}$ & $\begin{array}{l}E \text {, lower } \\
\text { CI }\end{array}$ & $\begin{array}{l}E \text {, upper } \\
\text { CI }\end{array}$ & $\begin{array}{l}\text { प्र० } 1 \\
0^{-3} \mathrm{~d}^{-2} \square\end{array}$ & $\log \square$ & $\begin{array}{l}\text { average } \\
\boldsymbol{E}_{\boldsymbol{R}}\left(10^{-3}\right) \\
\text { from } \boldsymbol{R}_{\text {eff }}\end{array}$ \\
\hline Alaska & $\mathrm{AK}$ & $\mathrm{N}$ & 19.6 & 19.8 & 20.8 & 11.49 & 14.09 & 11.23 & 0.587 & -0.096 & 14.23 \\
\hline Albania & ALB & $\mathrm{Y}$ & 36.6 & 35.9 & 36.9 & 8.19 & 10.02 & 8.02 & 0.224 & -0.293 & 11.94 \\
\hline Andorra & AND & $\mathrm{N}$ & 6.9 & 6.3 & 7.7 & 28.63 & 40.99 & 21.39 & 4.168 & 0.161 & 34.08 \\
\hline Australia & AUS & $\mathrm{Y}$ & 12 & 11.9 & 13.7 & 18.81 & 20.49 & 15.2 & 1.562 & 0.008 & 26.21 \\
\hline
\end{tabular}




\begin{tabular}{|c|c|c|c|c|c|c|c|c|c|c|c|}
\hline Austria & AUT & $\mathrm{Y}$ & 9.8 & 10.3 & 9.8 & 22.06 & 21.6 & 21.33 & 2.254 & 0.064 & 29.16 \\
\hline Belgium & BEL & $\mathrm{Y}$ & 35.2 & 33.9 & 36 & 5.67 & 6.01 & 5.78 & 0.161 & -0.197 & 10.04 \\
\hline $\begin{array}{l}\text { Bosnia } \\
\text { and } \\
\text { Herzegov } \\
\text { ina }\end{array}$ & BIH & $\mathrm{N}$ & 37 & 36 & 38.2 & 5.6 & 7.28 & 5.02 & 0.151 & -0.216 & 6.22 \\
\hline Bulgaria & BGR & $\mathrm{Y}$ & 7.1 & 5.9 & 7.3 & 24.74 & 32.76 & 22.98 & 3.499 & 0.18 & 28.63 \\
\hline Canada & CAN & $\mathrm{N}$ & 37.2 & 37.5 & 37.2 & 3.67 & 3.85 & 3.55 & 0.099 & -0.127 & 4.65 \\
\hline China & $\mathrm{CHN}$ & $\mathrm{X}$ & 10.1 & 11.1 & 9.8 & 18.93 & 17.24 & 19.93 & 1.865 & 0.081 & 23.87 \\
\hline Colorado & $\mathrm{CO}$ & $\mathrm{N}$ & 8 & 6.9 & 8.9 & 20.59 & 25.76 & 19.91 & 2.581 & 0.168 & 24.05 \\
\hline $\begin{array}{l}\text { Connecti } \\
\text { cut }\end{array}$ & $\mathrm{CT}$ & $\mathrm{N}$ & 20.3 & 19.8 & 20.3 & 8.91 & 12.57 & 8.11 & 0.439 & -0.056 & 11.06 \\
\hline Croatia & HRV & $\mathrm{N}$ & 13 & 12.3 & 13.3 & 14.05 & 16.05 & 13.39 & 1.082 & 0.039 & 26.59 \\
\hline Cyprus & CYP & $\mathrm{N}$ & 19.8 & 18.2 & 20.7 & 13.63 & 16.75 & 12.33 & 0.688 & -0.138 & 20.26 \\
\hline $\begin{array}{l}\text { Czech } \\
\text { Republic }\end{array}$ & CZE & $\mathrm{Y}$ & 20 & 16.7 & 20.2 & 8.95 & 10.63 & 9.6 & 0.447 & -0.051 & 13.46 \\
\hline Estonia & EST & $\mathrm{N}$ & 15.2 & 14.5 & 15.5 & 19.38 & 25.08 & 16.34 & 1.278 & -0.098 & 27.38 \\
\hline Finland & FIN & $\mathrm{N}$ & 5.3 & 5.3 & 5.5 & 26.88 & 36.14 & 19.77 & 5.029 & 0.284 & 29.65 \\
\hline Florida & FL & $\mathrm{N}$ & 25.1 & 25.4 & 24.8 & 5.93 & 6.65 & 6.16 & 0.236 & -0.059 & 7.89 \\
\hline France & FRA & $\mathrm{Y}$ & 18.3 & 17.4 & 18.5 & 9.2 & 11.06 & 8.56 & 0.503 & -0.018 & 11.49 \\
\hline Georgia & GEO & $\mathrm{N}$ & 22.6 & 21.8 & 23.1 & 12.39 & 15.66 & 11.57 & 0.547 & -0.175 & 16.59 \\
\hline Germany & DEU & $\mathrm{N}$ & 17.5 & 18.5 & 17.1 & 9.39 & 9.57 & 9.39 & 0.536 & -0.004 & 13.07 \\
\hline Greece & GRC & $\mathrm{Y}$ & 21.8 & 23.5 & 20 & 10.08 & 18.67 & 10 & 0.463 & -0.113 & 17.1 \\
\hline $\begin{array}{l}\text { Guangdo } \\
\text { ng }\end{array}$ & GD & $\mathrm{N}$ & 9.3 & 8.4 & 10.1 & 27.88 & 31.67 & 24.79 & 2.996 & 0.035 & 39.75 \\
\hline Guernsey & GGY & $\mathrm{Y}$ & 9.3 & 10.2 & 9.2 & 28.13 & 29.27 & 26.42 & 3.023 & 0.033 & 37.51 \\
\hline Hawaii & $\mathrm{HI}$ & $\mathrm{Y}$ & 9.3 & 9.2 & 9.5 & 19.76 & 23.98 & 17.05 & 2.126 & 0.11 & 23.59 \\
\hline Henan & $\mathrm{HA}$ & $\mathrm{N}$ & 13.3 & 12.5 & 13.6 & 20.14 & 21.85 & 19.52 & 1.51 & -0.051 & 30.08 \\
\hline $\begin{array}{l}\text { Hong } \\
\text { Kong }\end{array}$ & HKG & $\mathrm{N}$ & 8.7 & 9.3 & 8.5 & 21.1 & 20.6 & 22.4 & 2.424 & 0.125 & 24.63 \\
\hline Hubei & $\mathrm{HB}$ & $\mathrm{Y}$ & 9 & 7.6 & 9.1 & 23.22 & 27.06 & 22.18 & 2.577 & 0.089 & 30.35 \\
\hline Hunan & $\mathrm{HN}$ & $\mathrm{N}$ & 13.9 & 13.3 & 14.8 & 17.65 & 20.08 & 15.98 & 1.266 & -0.041 & 25.45 \\
\hline Hungary & HUN & $\mathrm{N}$ & 7.3 & 6.6 & 7.6 & 33.71 & 40.85 & 30.72 & 4.627 & 0.1 & 44.63 \\
\hline Iceland & ISL & $\mathrm{N}$ & 21.4 & 19.7 & 21.5 & 11.92 & 13.15 & 12.41 & 0.557 & -0.142 & 20.49 \\
\hline Idaho & ID & $\mathrm{N}$ & 7.9 & 7.5 & 8 & 42.29 & 46.75 & 39.51 & 5.375 & 0.017 & 59.97 \\
\hline Iowa & IA & $\mathrm{N}$ & 8.9 & 8 & 12.3 & 17.08 & 23.86 & 12.06 & 1.921 & 0.161 & 20.12 \\
\hline Iran & IRN & $\mathrm{N}$ & 10.3 & 9 & 11.5 & 15.82 & 19.19 & 14.26 & 1.529 & 0.112 & 20.05 \\
\hline Ireland & IRL & $\mathrm{Y}$ & 6.8 & 5 & 7.9 & 22.03 & 37.93 & 17.55 & 3.249 & 0.224 & 24.7 \\
\hline $\begin{array}{l}\text { Isle of } \\
\text { Man }\end{array}$ & IMN & $\mathrm{Y}$ & 15.8 & 14.5 & 16.5 & 17.23 & 27.31 & 15.6 & 1.087 & -0.092 & 22.5 \\
\hline Israel & ISR & $\mathrm{N}$ & 14.7 & 13.4 & 15.3 & 14.96 & 16.5 & 15 & 1.021 & -0.027 & 22.2 \\
\hline Italy & ITA & $\mathrm{Y}$ & 15.2 & 15.2 & 14.8 & 7.97 & 7.8 & 8.28 & 0.526 & 0.095 & 10.48 \\
\hline Jamaica & JAM & $\mathrm{N}$ & 18.1 & 17.4 & 19.1 & 16.83 & 24.08 & 13.37 & 0.929 & -0.145 & 28.85 \\
\hline Japan & JAP & $\mathrm{N}$ & 15.9 & 15.5 & 16 & 10.74 & 10.6 & 10.97 & 0.676 & 0.01 & 13.72 \\
\hline Jersey & JEY & $\mathrm{Y}$ & 10.5 & 13.7 & 9.5 & 20.93 & 29.55 & 19.4 & 1.988 & 0.044 & 27.56 \\
\hline Jordan & JOR & $\mathrm{Y}$ & 6.3 & 5 & 6.9 & 33.98 & 52.26 & 30.62 & 5.374 & 0.16 & 39.81 \\
\hline Kansas & $\mathrm{KS}$ & $\mathrm{N}$ & 21.9 & 21.9 & 21.3 & 8.59 & 11.48 & 7.41 & 0.393 & -0.081 & 13.19 \\
\hline Kosovo & KOS & $\mathrm{N}$ & 19.8 & 18.3 & 21 & 13.55 & 19.34 & 12.82 & 0.683 & -0.137 & 21.13 \\
\hline Latvia & LVA & $\mathrm{Y}$ & 8.4 & 8.8 & 8.5 & 18.32 & 22.71 & 17.21 & 2.174 & 0.169 & 33.21 \\
\hline Lebanon & LBN & $\mathrm{Y}$ & 7.2 & 5.7 & 8.9 & 27.46 & 49.3 & 21.48 & 3.825 & 0.151 & 39.68 \\
\hline Lithuania & LTU & $\mathrm{Y}$ & 32.9 & 31.5 & 34.7 & 9.25 & 11.49 & 8.96 & 0.281 & -0.274 & 23.69 \\
\hline Louisiana & LA & $\mathrm{Y}$ & 8.3 & 6.6 & 9.2 & 31.36 & 47.2 & 27.4 & 3.775 & 0.059 & 42.69 \\
\hline Luxembo & LUX & $\mathrm{N}$ & 19 & 19.9 & 17.8 & 11.66 & 14.08 & 11.87 & 0.613 & -0.086 & 17.12 \\
\hline
\end{tabular}




\begin{tabular}{|c|c|c|c|c|c|c|c|c|c|c|c|}
\hline urg & & & & & & & & & & & \\
\hline Malaysia & MYS & $\mathrm{N}$ & 34 & 33 & 34.6 & 6.82 & 7.58 & 6.47 & 0.2 & -0.222 & 13.92 \\
\hline Malta & MLT & $\mathrm{Y}$ & 7.6 & 6.7 & 9.7 & 37.16 & 62.48 & 24.99 & 4.879 & 0.06 & 46.91 \\
\hline $\begin{array}{l}\text { Massach } \\
\text { usetts }\end{array}$ & MA & $\mathrm{Y}$ & 8.2 & 7.5 & 8.9 & 19.49 & 21.03 & 18.06 & 2.367 & 0.166 & 22.42 \\
\hline Mauritius & MUS & $\mathrm{Y}$ & 7.5 & 5.5 & 7.7 & 37.05 & 67.36 & 32.62 & 4.95 & 0.068 & 50.61 \\
\hline Michigan & MI & $\mathrm{Y}$ & 9.5 & 8.8 & 10.3 & 18.2 & 20.64 & 16.25 & 1.909 & 0.117 & 23.74 \\
\hline Montana & MT & $\mathrm{Y}$ & 17 & 16.4 & 18 & 15.14 & 16.73 & 13.23 & 0.892 & -0.093 & 22.55 \\
\hline $\begin{array}{l}\text { Montene } \\
\text { gro }\end{array}$ & MNE & $\mathrm{N}$ & 6.4 & 5 & 7.3 & 52.98 & 76.69 & 42.65 & 8.282 & 0.058 & 72.22 \\
\hline Morocco & MAR & $\mathrm{N}$ & 29.7 & 27.7 & 31.2 & 7.03 & 8.99 & 6.98 & 0.237 & -0.17 & 8.92 \\
\hline $\begin{array}{l}\text { Netherlan } \\
\text { ds }\end{array}$ & NLD & $\mathrm{N}$ & 26.9 & 26.6 & 28.2 & 5.96 & 6.56 & 6.03 & 0.222 & -0.091 & 7.53 \\
\hline $\begin{array}{l}\text { New } \\
\text { Hampshir } \\
\text { e }\end{array}$ & $\mathrm{NH}$ & $\mathrm{Y}$ & 37.2 & 36.2 & 37.5 & 4.61 & 4.64 & 4.88 & 0.124 & -0.176 & 5.24 \\
\hline $\begin{array}{l}\text { New } \\
\text { Jersey }\end{array}$ & $\mathrm{NJ}$ & $\mathrm{Y}$ & 27 & 27.4 & 26.7 & 5.13 & 5.36 & 4.96 & 0.19 & -0.06 & 6.7 \\
\hline $\begin{array}{l}\text { New } \\
\text { York }\end{array}$ & NY & $\mathrm{Y}$ & 38.6 & 38.7 & 38.2 & 4.6 & 4.88 & 4.34 & 0.119 & -0.191 & 9 \\
\hline $\begin{array}{l}\text { New } \\
\text { Zealand }\end{array}$ & NZL & $\mathrm{Y}$ & 15.9 & 15.1 & 16.6 & 18.01 & 19.77 & 17.19 & 1.132 & -0.103 & 29.3 \\
\hline $\begin{array}{l}\text { North } \\
\text { Macedon } \\
\text { ia }\end{array}$ & MKD & $\mathrm{N}$ & 7 & 5.7 & 8.5 & 32.64 & 53.3 & 24.06 & 4.68 & 0.126 & 39.74 \\
\hline Norway & NOR & $\mathrm{Y}$ & 15.5 & 15.5 & 15.5 & 14.51 & 15.51 & 13.79 & 0.935 & -0.045 & 19.92 \\
\hline Oregon & OR & $\mathrm{Y}$ & 49.7 & 48.6 & 49.8 & 3.71 & 4.44 & 3.22 & 0.075 & -0.255 & 5.22 \\
\hline $\begin{array}{l}\text { Pennsylv } \\
\text { ania }\end{array}$ & PA & $\mathrm{Y}$ & 9.2 & 8.7 & 12.1 & 14.71 & 18.04 & 10.95 & 1.591 & 0.176 & 19.29 \\
\hline Portugal & POR & $\mathrm{N}$ & 20.5 & 18.4 & 20.8 & 9.19 & 11.02 & 9.19 & 0.449 & -0.067 & 12.7 \\
\hline Reunion & REU & $\mathrm{N}$ & 7.4 & 7.1 & 7.5 & 27.28 & 32.45 & 24.44 & 3.681 & 0.138 & 33.45 \\
\hline $\begin{array}{l}\text { Rhode } \\
\text { Island }\end{array}$ & RI & $\mathrm{N}$ & 21.2 & 20.3 & 21.7 & 7.57 & 8.42 & 7.18 & 0.357 & -0.04 & 11.58 \\
\hline Romania & ROU & $\mathrm{Y}$ & 45.8 & 47.2 & 46.1 & 3.14 & 3.29 & 3.21 & 0.069 & -0.183 & 5.68 \\
\hline Russia & RUS & $\mathrm{X}$ & 13.5 & 12.6 & 14.2 & 6.63 & 7.41 & 6.37 & 0.489 & 0.184 & 7.74 \\
\hline $\begin{array}{l}\text { San } \\
\text { Marino }\end{array}$ & SMR & $\mathrm{Y}$ & 23.8 & 24.1 & 23.3 & 12.57 & 20.91 & 9.8 & 0.528 & -0.2 & 17.21 \\
\hline Serbia & SRB & $\mathrm{N}$ & 6.9 & 6 & 7.6 & 25.09 & 29.94 & 22.69 & 3.639 & 0.188 & 29.1 \\
\hline $\begin{array}{l}\text { Singapor } \\
\mathrm{e}\end{array}$ & SGP & $\mathrm{Y}$ & 8.4 & 7.7 & 9 & 24.35 & 29.81 & 22.35 & 2.913 & 0.111 & 30.15 \\
\hline Slovakia & SVK & $\mathrm{N}$ & 7.6 & 6.3 & 8.5 & 32.39 & 59.38 & 26.73 & 4.262 & 0.09 & 39.19 \\
\hline Slovenia & SVN & $\mathrm{N}$ & 9.2 & 8.8 & 9.6 & 18.49 & 20.65 & 17.03 & 2.015 & 0.13 & 22.05 \\
\hline $\begin{array}{l}\text { South } \\
\text { Korea }\end{array}$ & KOR & $\mathrm{N}$ & 8.3 & 7.2 & 9 & 37.58 & 44.25 & 36.57 & 4.514 & 0.018 & 51.06 \\
\hline Spain & ESP & $\mathrm{Y}$ & 15.3 & 17.1 & 14.5 & 10.15 & 9.59 & 11.19 & 0.662 & 0.037 & 12.86 \\
\hline Sweden & SWE & $\mathrm{N}$ & 32 & 33.2 & 33.8 & 4.55 & 5.72 & 3.67 & 0.142 & -0.108 & 5.02 \\
\hline $\begin{array}{l}\text { Switzerla } \\
\text { nd }\end{array}$ & $\mathrm{CHE}$ & $\mathrm{N}$ & 22 & 22.2 & 21.5 & 8.61 & 9.4 & 8.06 & 0.392 & -0.084 & 6.08 \\
\hline Taiwan & TWN & $\mathrm{N}$ & 11.2 & 10.6 & 12.3 & 20.78 & 24.84 & 18.04 & 1.853 & 0.018 & 29.87 \\
\hline Thailand & THA & $\mathrm{N}$ & 15.5 & 13.8 & 16.1 & 14.87 & 19.61 & 14.29 & 0.961 & -0.049 & 22.3 \\
\hline Tunisia & TUN & $\mathrm{N}$ & 26.4 & 25.7 & 27 & 10.91 & 14.25 & 9.5 & 0.413 & -0.215 & 15.12 \\
\hline Turkey & TYR & $\mathrm{N}$ & 16.3 & 16.1 & 17.3 & 8.27 & 8.82 & 7.72 & 0.508 & 0.055 & 10.35 \\
\hline United & GBR & $\mathrm{Y}$ & 41.8 & 42.8 & 41.8 & 3.07 & 2.94 & 3.32 & 0.073 & -0.138 & 4.5 \\
\hline
\end{tabular}




\begin{tabular}{|c|c|c|c|c|c|c|c|c|c|c|c|}
\hline Kingdom & & & & & & & & & & & \\
\hline $\begin{array}{l}\text { United } \\
\text { States }\end{array}$ & USA & $\mathrm{X}$ & 37.9 & 39.2 & 37.5 & 2.78 & 2.66 & 2.96 & 0.073 & -0.074 & 3.68 \\
\hline Uruguay & URY & $\mathrm{N}$ & 27.5 & 26.5 & 29 & 11.87 & 17.27 & 9.93 & 0.432 & -0.249 & 24.1 \\
\hline $\begin{array}{l}\text { Uzbekist } \\
\text { an }\end{array}$ & UZB & $\mathrm{N}$ & 7.3 & 5.6 & 7.2 & 30.46 & 48.27 & 30.1 & 4.146 & 0.118 & 36.64 \\
\hline Vermont & VT & $\mathrm{N}$ & 8.5 & 8.4 & 8.7 & 24.63 & 27.65 & 24.24 & 2.892 & 0.1 & 29.57 \\
\hline Vietnam & VNM & $\mathrm{N}$ & 14.4 & 13.9 & 14.8 & 15.51 & 19.92 & 12.83 & 1.076 & -0.028 & 20.59 \\
\hline $\begin{array}{l}\text { Washingt } \\
\text { on }\end{array}$ & WA & $\mathrm{N}$ & 16.9 & 15.7 & 17.5 & 9.38 & 10.35 & 9.35 & 0.555 & 0.012 & 13.15 \\
\hline Zhejiang & $\mathrm{ZJ}$ & $\mathrm{N}$ & 8.8 & 8.6 & 8.9 & 35.46 & 36.22 & 34.49 & 4.049 & 0.009 & 47.49 \\
\hline
\end{tabular}

\section{RESULTS}

\section{1) Practical explanation of effectiveness parameters}

Very efficient preventive measures implemented are associated with a short $T_{E}$ and a great $\bar{E}$ and $\square$.

Table 1 shows the data of countries and states whose effective phases ended before 16 May 2020. From this table, the average duration of the effective phase $T_{E}$ was $17.3 \pm 10.5 \mathrm{~d}(5.3-49.7$, range $44.4 \mathrm{~d})$. The average effectiveness $\bar{E}$ was $17.0 \cdot 10^{-3} \pm 10.3 \cdot 10^{-3} \mathrm{~d}^{-2}\left(2.8 \cdot 10^{-3}-53.0 \cdot 10^{-3}\right.$, range $\left.50.2 \cdot 10^{-3} \mathrm{~d}^{-2}\right)$. The average of the ratio $\square$ was $1.73 \cdot 10^{-3} \pm 1.70 \cdot 10^{-3} \mathrm{~d}^{-3}\left(0.07 \cdot 10^{-3}-8.28 \cdot 10^{-3}\right.$, range $\left.8.21 \cdot 10^{-3} \mathrm{~d}^{-3}\right)$.

The effectiveness parameters are exemplified by four countries in Figure 2.

Australia follows a (slightly asymmetrical) Gaussian velocity profile (log $\square=+0.01$, close to 0 ) of medium effectiveness $\left(18.8 \cdot 10^{-3} \mathrm{~d}^{-2}\right.$, close to the overall country average), medium duration of the effective phase of $12.0 \mathrm{~d}$ (still shorter than the overall country average), and $\square$ of $1.56 \cdot 10^{-3} \mathrm{~d}^{-3}$ (close to the overall country average).

Ireland exhibits a triangular velocity profile $(\log \square=+0.22)$ of medium-to-high effectiveness $\left(22.0 \cdot 10^{-3}\right.$ $\mathrm{d}^{-2}$ ), short duration of the effective phase of $6.8 \mathrm{~d}$, and high $\square$ of $3.25 \cdot 10^{-3}$ (twice a high as Australia).

New Zealand is characterised by a short trapezoidal velocity profile ( $\log \square=-0.10$ ) of medium effectiveness $\left(18.0 \cdot 10^{-3} \mathrm{~d}^{-2}\right.$, same as Australia, close to the overall country average), medium duration of $15.9 \mathrm{~d}$ (close to the overall country average), and smaller $\square$ of $1.13 \cdot 10^{-3}$.

Malaysia is affected by a long trapezoidal velocity profile ( $\log \square=-0.22$ ) of very low effectiveness $\left(6.8 \cdot 10^{-3} \mathrm{~d}^{-2}\right)$, a long duration of $34.0 \mathrm{~d}$ (twice the overall country average), and an ineffective $\square$ of $0.20 \cdot 10^{-3}$.

In general, long trapezoidal plateaus are subjected to fluctuations, which render the plateau alternating effective and ineffective. In the short trapezoidal plateau of New Zealand (Figure 2c), the plateau is 
almost flat which makes the effectiveness profile double-humped, with zero-effectiveness between the two humps.
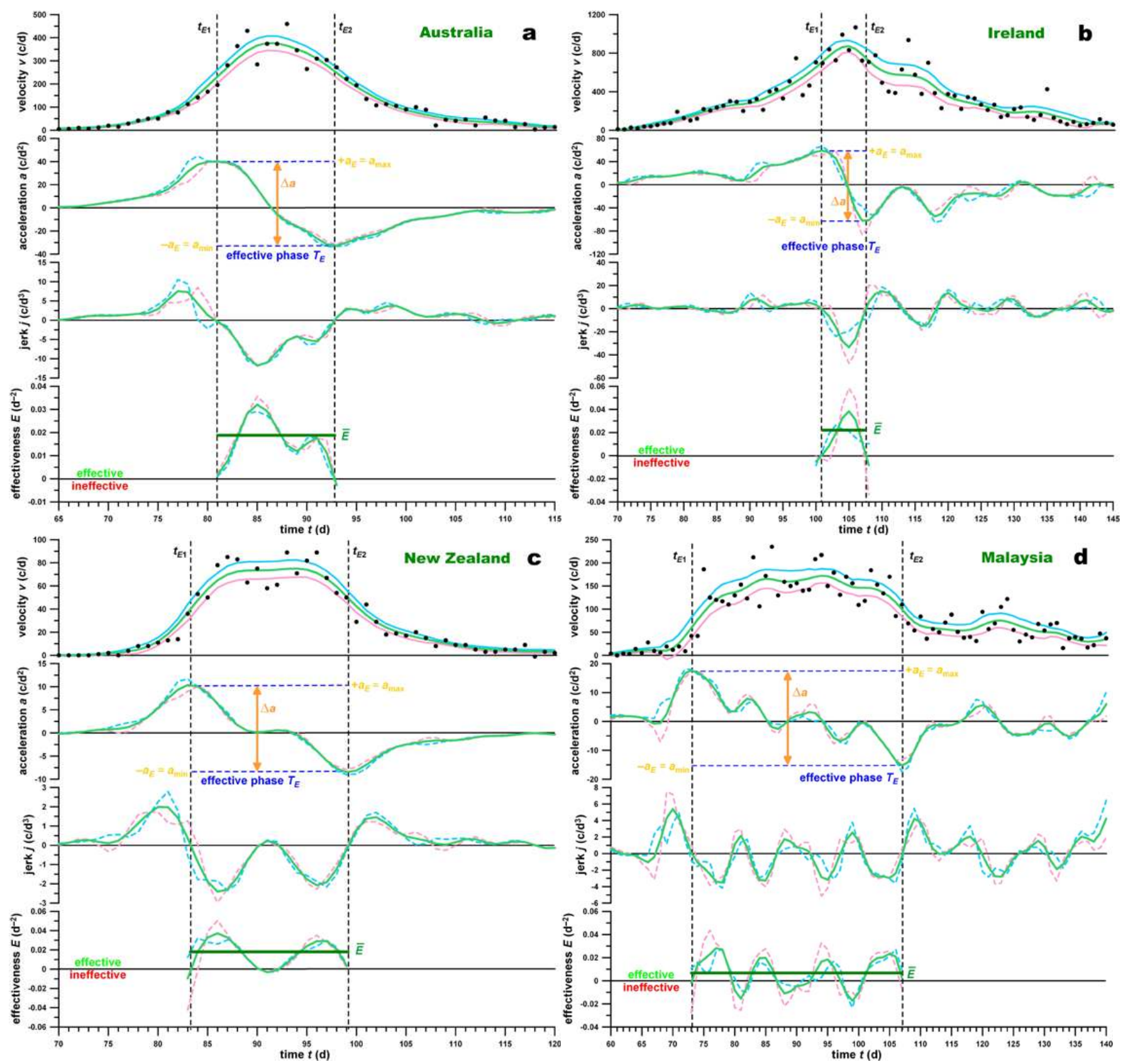

Figure 2: velocity, acceleration, jerk and effectiveness of the spreading virus against time (day $1=01 / 01 / 2020$ ) for 4 different velocity profiles: a: Gaussian (Australia, $\log \square=+0.01$, medium effective $\square=1.56 \cdot 10^{-3}$ ), b: triangular (Ireland, $\log \square=+0.22$, very effective $\square=3.25 \cdot 10^{-3}$ ), c: short trapezoidal (New Zealand, $\log \square=-0.10$, medium effective $\square=1.13 \cdot 10^{-3}$ ); d: long trapezoidal (Malaysia, $\log \square=-0.22$, ineffective $\square=0.20 \cdot 10^{-3}$ ); green curve: filtered velocity data and their time derivatives; light blue and pink curves denote upper and lower confidence intervals (note that after differentiation, upper and lower boundaries can switch their positions); $t_{E 1,2}=$ start and end of effective phase; $a=$ acceleration; 


\section{2) Interrelationship of effectiveness parameters}

Figure 3 shows the relationship between $\bar{E}$ and $T_{E}$, with respect to hypothetical data of a Gaussian function (separating triangular and trapezoidal $v$-profiles). The point map and its power-law fit function $\left(\mathrm{R}^{2}=0.8337\right)$ deviate from, and cross over, the hypothetical Gaussian function data. The data can be divided into three areas: velocity data profiles ranging between Gaussian and triangular with high effectiveness (green area); profiles ranging from triangular over Gaussian to trapezoidal with medium effectiveness (yellow area); and profiles ranging from Gaussian to trapezoidal with low effectiveness (pink area). Figure 3 shows that there are no ineffective triangular velocity profiles and no highly effective trapezoidal profiles. Figure 4 shows $\bar{E}, T_{E}, \square$ and $\log \square$ colour-coded on the country map of Europe. Finland had the shortest effective phase $(5.3 \mathrm{~d})$ and Romania the longest $(45.8 \mathrm{~d})$. The least and most effective countries $(\bar{E})$ were Great Britain $\left(3.1 \cdot 10^{-3}\right)$ and Montenegro $\left(53.0 \cdot 10^{-3}\right)$, respectively (Figure 4).
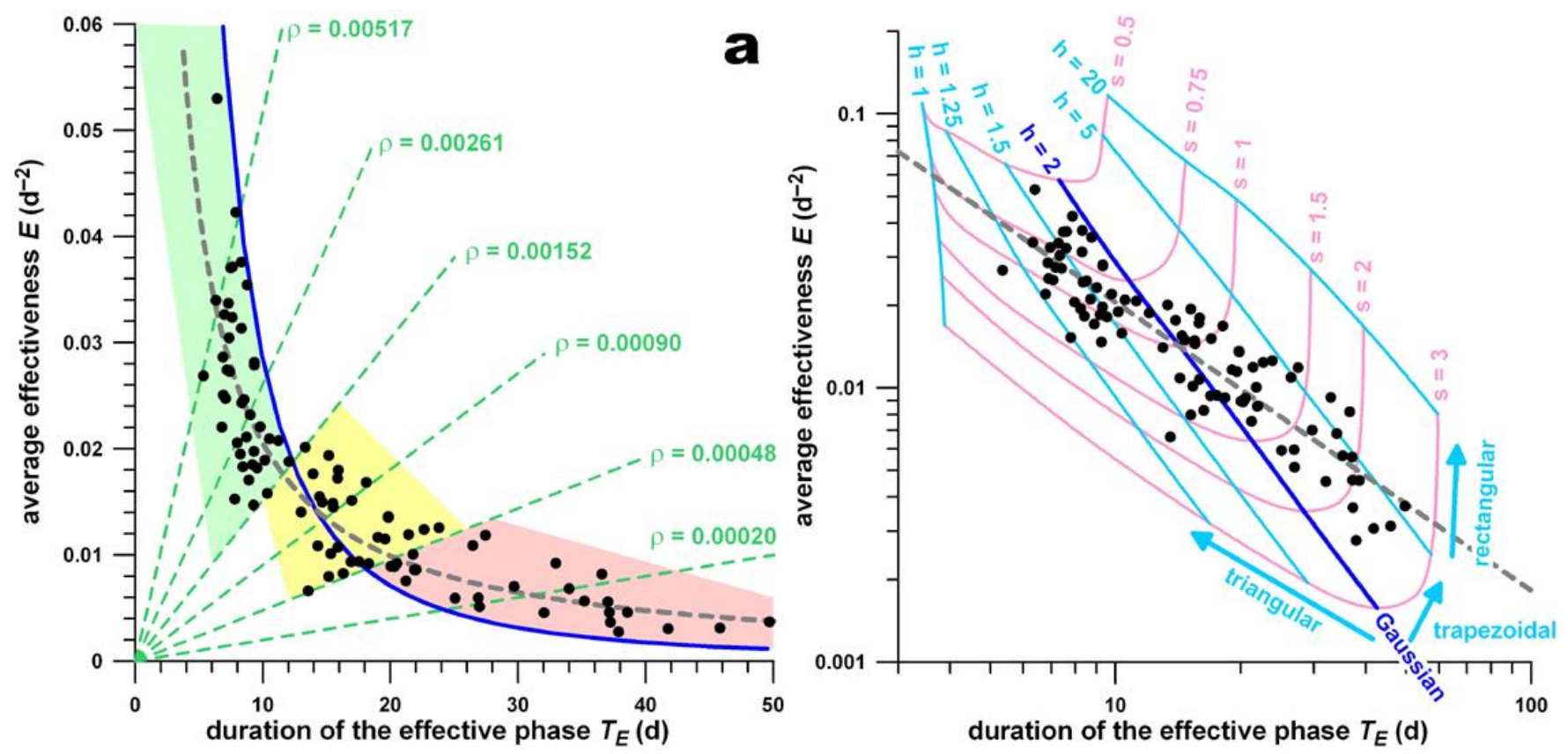

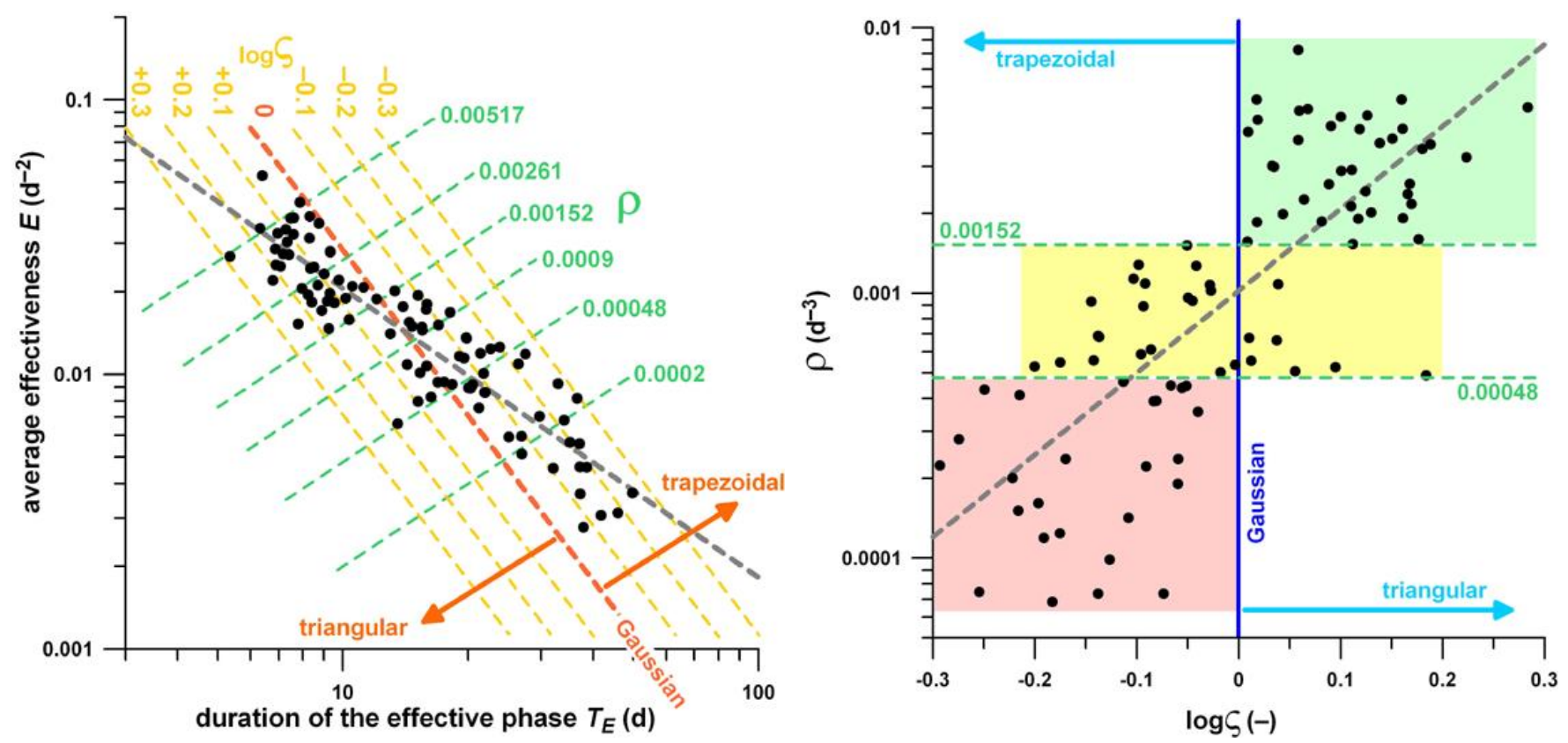

Figure 3:

a: average effectiveness ( $\bar{E})$ against the duration of the effective phase $\left(T_{E}\right)$; blue curve: Gaussian function; green area: velocity profiles between triangular and Gaussian; yellow area: velocity profile transition from triangular across Gaussian to trapezoidal; pink area: velocity profiles between Gaussian and trapezoidal; dark-green dashed lines: isolines of the $\bar{E} / T_{E}$ ratio $(\square)$; dashed black curve: power function fit of all data; note that data located on the blue curve (Gaussian function) are not necessarily Gaussian but can be pseudo-Gaussian, as the transition from triangular to trapezoid velocity profile (as shown in subfigure $3 \mathbf{b}$ ) can be a very short trapezoid plateau (shorter than the one of New Zealand shown in Figure 2b).

b: average effectiveness $(\bar{E})$ against the duration of the effective phase $\left(T_{E}\right)$ on a double-logarithmic graph; the pink lines are isolines of the shape parameter $s$, associated with the width of the velocity profile (the smaller $s$, the more effective); the light-blue lines are isolines of shape parameter $h$, associated with the shape of the velocity profile, indicating the transition from triangular velocity profile over Gaussian and trapezoidal to a hypothetical rectangular profile.

c: average effectiveness $(\bar{E})$ against the duration of the effective phase $\left(T_{E}\right)$ on a double-logarithmic graph; parameter $\square$ is the ratio of $\bar{E}$ to $T_{E}$, (the greater, the more effective); parameter $\square$ is another parameter associated with the shape of the velocity profile, which indicates the transition from triangular velocity profile over Gaussian to a trapezoidal profile.

d: $\square$ against $\log \square$ on a single-logarithmic graph; the green, yellow and pink areas correspond to the ones shown in (a). 

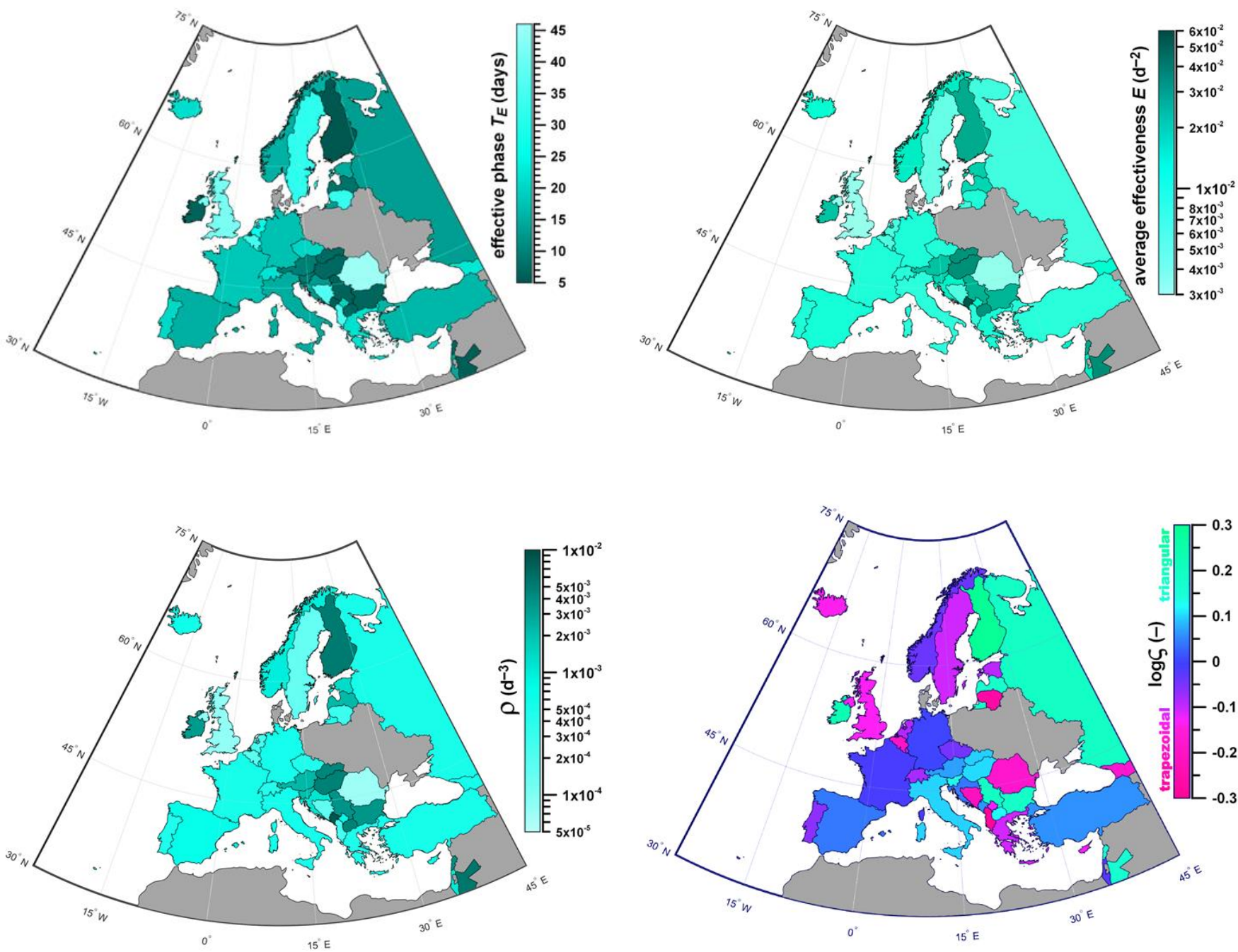

Figure 4: Maps of Europe, showing the effectiveness of control measures of each country, for countries whose effective phase $T_{E}$ ended the latest on 15 May 2020; upper row: (a): duration of effective phase $T_{E}$; (b) average effectiveness $\bar{E}$; (c) $\square\left(\bar{E} / T_{E}\right.$ ratio); (d) $\log \square$ (shape parameter: blue: Gaussian velocity profile, green: triangular velocity profile, red: trapezoidal velocity profile); for subfigures (a), (b) and (c): the darker the more effective.

$\bar{E}$ is directly related to $\bar{E}_{R}$, the effectiveness calculated from $R_{e f f}$, as shown in Figure 5a. The slope of the regression line is 1.2656 and not 1.41 according to Eqn (22), which is applicable to Gaussian functions only. The intercept of the regression function is very close to 0 . In Figure $5 b$, the regression slope of $\bar{E}_{R}$ vs $\bar{E}$ is plotted against the averages of $\log \square$ showing that the slope decreases as $\log \square$ increases. The intercept of the regression function is 1.4003 , which corresponds to the slope predicted at $\log \square=0$ and is close to the predicted multiplier of 1.41 according to Eqn (22). Figure 5 proves that $\bar{E}$ and $\bar{E}_{R}$ are comparable and complementary measures.

The magnitude of $\bar{E}_{R}$ is $94.80 \%$ explained from $\bar{E}\left(100 \mathrm{R}^{2}\right.$; Figure 5a); and $22.61 \%$ from $\log \square$. The multiple regression dependency of $\bar{E}_{R}$ is $96.19 \%$ on $\bar{E}$ and $\log \square$. In only $3.81 \%$, the dependency of $\bar{E}_{R}$ 
remains unexplained. The individual influences (semi-partial correlations) of $\bar{E}$ and $\log \square$ on $\bar{E}_{R}$ were $73.58 \%$ and $1.39 \%$, respectively, and the combined influence of $\bar{E}$ and $\log \square$ on $\bar{E}_{R}$ was $21.11 \%$. The semi- partial correlations revealed that any influence of $\log \square$ on $\bar{E}_{R}$ happened only in combination with $\bar{E}$. The reason for this could be explained from the fact that $\log \square$ is $43.41 \%$ influenced by $\bar{E}$, and even $44.66 \%$ by $\bar{E}<0.03$. More efficient countries tend to have a triangular $v$-profile, whereas less efficient countries are characterised by a more trapezoidal $v$-profile.
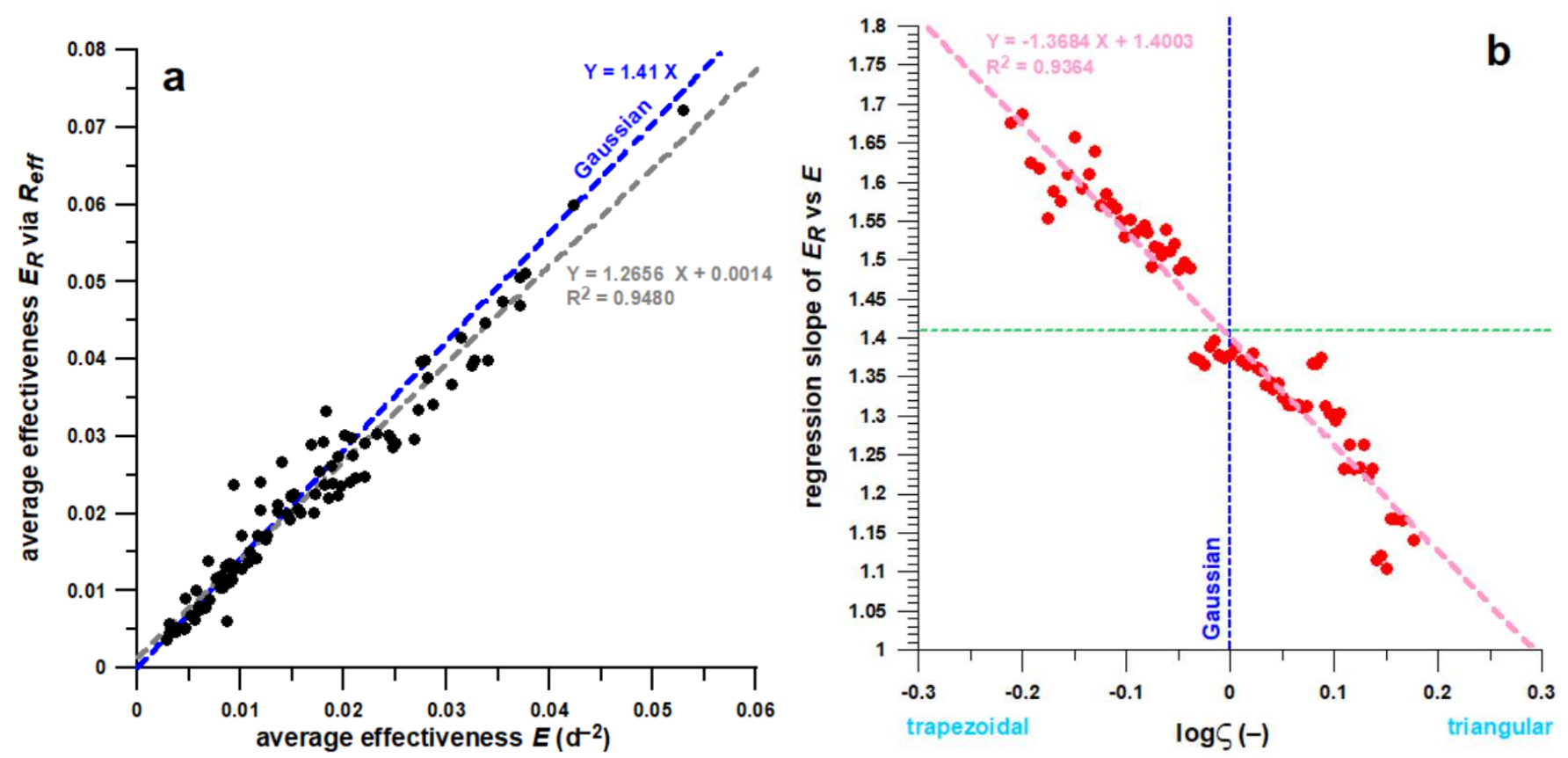

Figure 5: average effectiveness $\bar{E}_{R}$ calculated from the effective reproductive number $R_{\text {eff }}$ against the average effectiveness $\bar{E}$ (a) and slope of the regression of $\bar{E}_{R}$ vs $\bar{E}$ (b); in (a), the dashed grey line represents the linear fit function of the regression, whereas the dashed blue line represents the function expected from a Gaussian model; in (b), to assess the dependency of the regression slope on the shape parameter $\log \square$, the data of $\bar{E}, \bar{E}_{R}$ and $\log \square$ were sorted with respect to $\log \square$; and the averages of $\log \square$ and the regression slope of $\bar{E}_{R}$ vs $\bar{E}$ were calculated across a running window of 15 data; dashed green line: slope value expected from a Gaussian model; dashed blue line: Gaussian model data at $\log \square=0$.

\section{3) Timeline graphs of the effectiveness}

Figure 6 shows the timeline of the effectiveness. The first cluster was China and its provinces, followed by South Korea about a month later. 8 days after Korea left the effective phase, Malaysia started with her effective phase, followed by Uruguay, Iceland, Italy, Thailand and Switzerland. The first countries that left the effective phase, were: Lebanon; followed by Jordan, Massachusetts and Taiwan on the same day; 
followed by Andorra. The 5 most effective countries and states with the greatest $(\bar{E})$ were Montenegro, Idaho, South Korea, Malta and Mauritius.
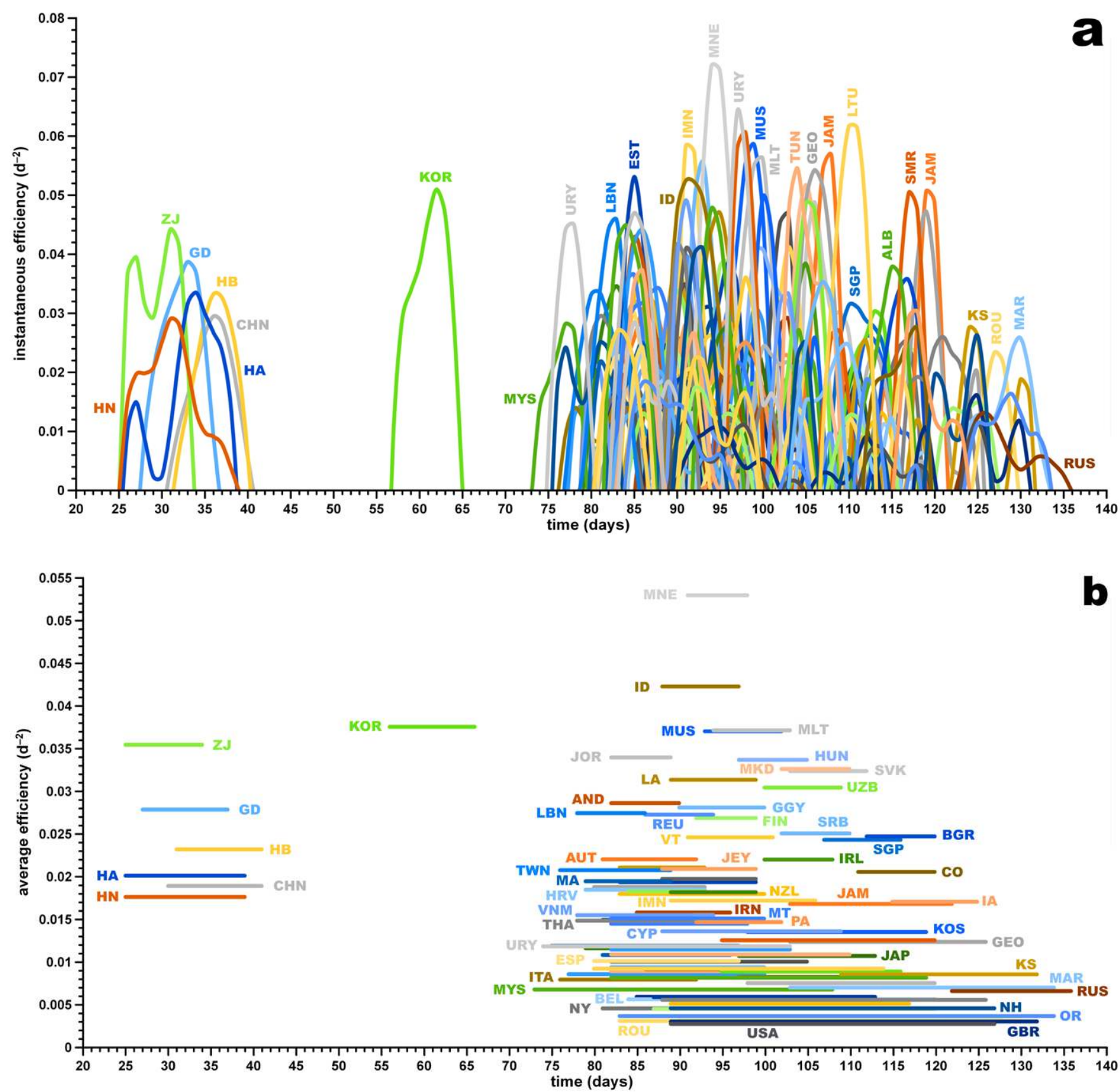

Figure 6: instantaneous effectiveness $E$ (a) and average effectiveness $\bar{E}$ (b) against time in days (day $1=$ 01/01/2020) for countries, states and provinces whose effective phase ended the latest on 15 May 2020; 3-letter country codes according to ISO 3166-1 Alpha-3; Chinese provinces 2-letter codes: ISO 3166-2:CN; 2-letter code of the states of the USA: ISO 3166-2:US; KOS = Kosovo; note that countries can exhibit multiple effectiveness peaks, as seen in (a) for Uruguay and some Chinese provinces, and in Figure 2. 
Table 2: Medians and significance testing (Mann-Whitney U-test; MWU) of the effectiveness parameters, comparing countries/states/provinces with lockdown to without lockdown listed in Table 1; (effect size $r$ interpretation according to McGrath and $\mathrm{Meyer}^{26}$ ); IQR = interquartile range, $T_{E}=$ duration of effective phase; $\bar{E}$ = effectiveness; $\square=\bar{E} / T_{E}$.

\begin{tabular}{|c|c|c|c|}
\hline & $T_{E}(\mathrm{~d})$ & $\bar{E}\left(\mathrm{~d}^{-2} \cdot 10^{-3}\right)$ & $\square\left(\mathrm{d}^{-3} 10^{-3}\right)$ \\
\hline $\begin{array}{l}\text { Median (IQR) no lock-down (n } \\
=37)\end{array}$ & $15.32(12.61)$ & $14.9(15.4)$ & $0.99(2.47)$ \\
\hline $\begin{array}{l}\text { Median (IQR) lock-down }(\mathrm{n}= \\
\text { 52) }\end{array}$ & $15.16(15.39)$ & $17.2(13.1)$ & $1.13(2.13)$ \\
\hline MWU p-value $(\square=0.05)$ & 0.8415 & 0.7642 & 0.7642 \\
\hline $\mathrm{U}$ & 986 & 999 & 998 \\
\hline Effect size $r$ & 0.0249 & 0.0385 & 0.0374 \\
\hline$r$ interpretation & very small $(r<0.1)$ & very small $(r<0.1)$ & very small $(r<0.1)$ \\
\hline
\end{tabular}

\section{4) Comparison of the effectiveness of control measures}

In 37 countries, lock-down measures were implemented as defined in the Methods section. 52 countries, were classified as no-lockdown. Although the medians follow the expected trend, i.e. lock-down measures are more effective with a shorter effective phase, the medians are statistically identical ( $p$ > 0.76, Table 2). The effect sizes were 'very small' for all 3 parameters. The box-whisker plots of the 3 effectiveness parameters are shown in Figure 7a-c. These results show clearly that drastic lock-down measures are not more efficient than less severe control measures.

The time between the first day of drastic lockdown measures and the first day of the effective phase was $5.53 \pm 6.01 \mathrm{~d}$ on average $(-8-22 \mathrm{~d}$, range $30 \mathrm{~d}$; Figure $7 \mathrm{~d})$. The negative data result from the fact that, as the commencement of the effective phase is a priory unknown, lockdown measures can very well be implemented during, and not before, the effective phase. 

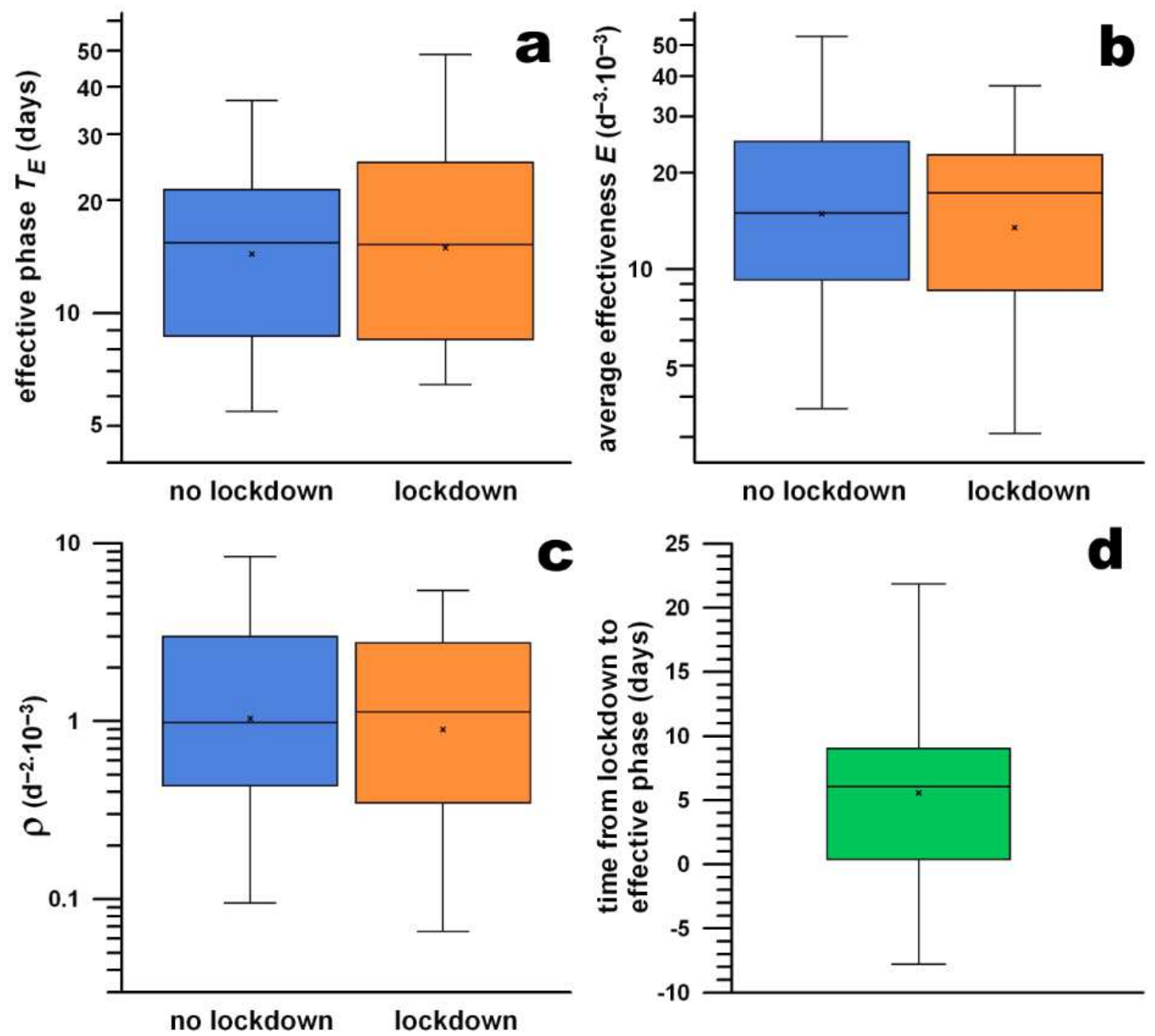

Figure 7: comparison of countries with and without lockdown measures for $T_{E}(\mathbf{a}), \bar{E}$ (b), and $\square$ (c) by means of Box-Whisker plots; (d) time between the first day of lockdown and the first day of $T_{E}$.

Table 3: Mortality (no. of deaths per million population), medians and significance testing (Mann-Whitney U-test; MWU) comparing countries/states/provinces with lockdown to without lockdown; and with mortality at middle of effective phase of greater and smaller 50 deaths per million population; interpretation of the effect size $r$ according to McGrath and Meyer [26])

\begin{tabular}{|c|c|c|c|c|c|c|c|c|}
\hline $\begin{array}{l}\text { Mortality } \\
\text { (deaths per } \\
\text { million } \\
\text { population) }\end{array}$ & $\begin{array}{l}\text { Median } \\
(\mathrm{IQR})- \\
\text { lockdown }\end{array}$ & $\begin{array}{l}\text { Median } \\
(\mathrm{IQR})- \\
\text { no } \\
\text { lockdown }\end{array}$ & $\begin{array}{l}\text { n1 - } \\
\text { lockdown }\end{array}$ & $\begin{array}{l}\text { n2-no } \\
\text { lockdown }\end{array}$ & $\begin{array}{l}\text { MWU } \\
\text { p-value } \\
(\square= \\
0.05)\end{array}$ & U & $\begin{array}{l}\text { Effect } \\
\text { size } r\end{array}$ & interpretation \\
\hline $\begin{array}{l}\text { at } \\
\text { beginning } \\
\text { of effective } \\
\text { phase }\end{array}$ & $2.3(18.2)$ & $2.7(10.1)$ & 37 & 47 & 0.7039 & 826.5 & 0.049454 & $\begin{array}{l}\text { very small }(r \\
<0.1)\end{array}$ \\
\hline $\begin{array}{l}\text { at middle } \\
\text { of effective } \\
\text { phase }\end{array}$ & $12(74.4)$ & $6.7(32.6)$ & 37 & 47 & 0.1031 & 688 & 0.208741 & $\begin{array}{l}\text { small }(0.1< \\
r<0.24)\end{array}$ \\
\hline
\end{tabular}




\begin{tabular}{|c|c|c|c|c|c|c|c|c|}
\hline $\begin{array}{l}\text { at end of } \\
\text { effective } \\
\text { phase }\end{array}$ & $24(116.3)$ & $\begin{array}{r}15.8 \\
(41.1)\end{array}$ & 37 & 47 & 0.1052 & 689 & 0.207591 & $\begin{array}{l}\text { small }(0.1< \\
r<0.24)\end{array}$ \\
\hline $\begin{array}{l}\text { at } \\
26 / 06 / 2020\end{array}$ & $\begin{array}{r}80.6 \\
(580.3)\end{array}$ & $\begin{array}{r}37.3 \\
(128.6)\end{array}$ & 37 & 52 & 0.0085 & 645 & 0.329522 & $\begin{array}{l}\text { medium } \\
(0.24<r< \\
0.37)\end{array}$ \\
\hline $\begin{array}{l}\text { Mortality } \\
\text { (deaths per } \\
\text { million } \\
\text { population) }\end{array}$ & $\begin{array}{l}\text { Median } \\
\text { (IQR) - } \\
\text { mortality } \\
\text { at middle } \\
\text { of } \\
\text { effective } \\
\text { phase > } \\
50 / \mathrm{M}\end{array}$ & $\begin{array}{l}\text { Median } \\
(\mathrm{IQR}) \text { - } \\
\text { mortality } \\
\text { at middle } \\
\text { of } \\
\text { effective } \\
\text { phase < } \\
50 / \mathrm{M}\end{array}$ & $\begin{array}{l}\mathrm{n} 1- \\
\text { mortality } \\
\text { at middle } \\
\text { of } \\
\text { effective } \\
\text { phase > } \\
50 / \mathrm{M}\end{array}$ & $\begin{array}{l}\mathrm{n} 2- \\
\text { mortality } \\
\text { at middle } \\
\text { of } \\
\text { effective } \\
\text { phase < } \\
50 / \mathrm{M}\end{array}$ & $\mathrm{p}$ & U2 & $\mathrm{r}$ & interpretation \\
\hline $\begin{array}{l}\text { at } \\
26 / 06 / 2020\end{array}$ & $\begin{array}{l}614.5 \\
(525.2)\end{array}$ & $\begin{array}{l}32.3 \\
(78.3)\end{array}$ & 67 & 19 & $<0.0001$ & 25 & 0.960723 & $\begin{array}{l}\text { large }(r> \\
0.37)\end{array}$ \\
\hline
\end{tabular}

\section{5) Mortality rate}

Comparing the mortality of lockdown and no lockdown countries at the beginning, middle and end of the effective phase did not reveal any significant difference (Table 3). The only significant difference was found when comparing the mortality data of 26/06/2020 with a medium effect size, and a higher mortality for countries with lockdown (Table 3). To investigate this result further, we divided the mortality data in the middle of the effective phase in two groups (greater or smaller than 50 deaths per one million population). The associated mortality data of 26/06/2020 are significantly different between, and directly correlated with, these two groups (Table 3). This result indicates that the lockdown countries in the higher mortality group (as of middle of effective phase) were not able to flatten the mortality curve better than the non-lockdown countries despite lockdown measures. The significantly higher mortality rate of lockdown countries as of $26 / 06 / 2020$ is explained simply from the fact that more countries with lockdown had a higher mortality since the effective phase than countries without lockdown. 


\section{DISCUSSION:}

The objective of our study was to develop a method for measuring the effectiveness of control measures on decreasing the transmission of the SARS-2-Coronavirus.

The most striking result of our study was that no significant difference in terms of the effectiveness of control measures could be found between countries (and states / provinces) with and without lockdown measures. This result has serious implications for the management of control measures.

First, our study provides the necessary evidence for Anders Tegnell's comment that 'lockdown' has no 'historical scientific basis' (for being efficient).

Second, the 'fine balance' [2] (between saving lives and saving the economy) is not immediately valid anymore, as the allegedly efficient lockdown is supposed to save lives, but also - as a side effect - brings the economy down. Countries with lockdown are as efficient as countries without - on average (based on the comparisons of medians). There was also no evidence that lockdown measures manage the mortality (deaths per population) better than measures without lockdown.

The statements 'the case for shutdown clear' and 'the shutdown wins' [4] are therefore no longer valid either, as the losses from COVID-19 casualties per population depend on the mortality during the effective phase rather than on lockdown measures themselves, and the burden of the economic downturn after lockdown still affects these very countries. It must be emphasised, though, that these conclusions are valid across a range of countries in terms of average or median data, whereas individual countries will respond differently to lockdown or no lockdown, in terms of effectiveness.

Other noteworthy results are that the time between the first day of drastic lockdown measures and the first day of the effective phase was $5.6 \mathrm{~d}$ on average, which is slightly longer than the serial interval of COVID-19, which is on average 5 days (cf. various literature sources listed in the Introduction). However, this period fluctuates and can even be negative, i.e. lockdown after the onset of the effective phase. This result demonstrates that control measures in the absence of any lockdown are already efficient on their own accord, as seen in countries without lockdown measures.

If lockdown measures are not more effective than measures without lockdown, what are the drivers of effectiveness in the absence of lockdown measures, that help keep the economy alive?

According to MacIntyre [27], 'In the absence of a vaccine, control of COVID-19 relies on four main strategies.' These strategies are: (1) identification of new cases and isolating them; (2) contacts tracking and quarantining; (3) personal protection; and (4) travel restrictions. Strategy no. 3 refers to 'social distancing, ranging from spatial separation of 1-2 $m$ to banning of mass gatherings and imposing lockdowns.' [27]. Typical lockdown measures are part of only the $3^{\text {rd }}$ strategy, as one extreme of a wide range of measures. The minimum requirement of strategy 3 was addressed by Chu et al. [27], who found 
in a meta-analysis review of physical distancing, face masks and eye-protection that 'no intervention, even when properly used, was associated with complete protection from infection.' These findings [27] seem to support many countries' decision for advising or compulsory requiring wearing face masks in public such as Canada, South Korea, the Czech Republic and Austria.

Why do countries respond differently to strategies and measures for controlling COVID-19? Why do some countries suffer from long plateaus of daily case data despite control measures and even lockdown measures?

The effectiveness of physical distancing and wearing personal protective equipment depends on the compliance of the citizens. Being compliant with control measures, however, is not just an expression of personal protection, but even more so 'shifts the focus ... to altruism, actively involves every citizen, and is a symbol of social solidarity in the global response to the pandemic' [29]. Compliance is mainly driven by the 'duty to obey authorities and personal morality' rather than by 'perceived risk of legal sanctions and perceived risk of the virus' [30]. A lockdown is nothing but enforcing compliance, specifically by rules, law, police, and fines, which in turn risks 'increasing non-compliance (or so-called lockdown fatigue [31])'. A compliance study [30] that investigated the compliance of Australian citizens during the (first) lockdown revealed that the participants' non-compliance was approximately $50 \%$ for each of the following reasons: "socialised in person with friends/relatives" they did not live with and "left the house without a really good reason". This striking behaviour of non-compliance with strict lockdown rules and measures resulted in a medium effectiveness of control measures, close to the averages of the data shown in Table 1.

Another important driver of compliance, often overlooked and underestimated, is 'that persuasion and education encourage normative compliance with rules and laws, because they promote a sense that people should comply with laws because it is the right thing to do' [32]. Proper education is facilitated by leadership by example, exhibited by leading politicians and scientists on the mass media and in public [33], e.g. by wearing masks, demonstrating good physical distancing practice, information session led by epidemiologists, etc. Leaders should refrain from conveying anecdotic evidence, such as which medication or personal measures could protect from attracting COVID-19.

A favourable approach for both controlling a virus outbreak and saving the economy of a country, would involve 1) an early start with control measures, even before case zero; 2) improvement of compliance by thorough education, information and explanation of the restrictions and appealing to the solidarity and morality of the people; and adopting economy-friendly but outbreak-preventive control measures in the absence of lockdown rules. 
It will take time and further research to align the hitherto contrary priorities - saving lives and preserving the economy - and provide a comprehensive and holistic strategy based on lessons learnt from the COVID-19 crisis. Considering that we have to deal with such a pandemic for the first time after 100 years, the inexperience of fighting this battle contributes decisively to the varying effectiveness of control measures.

\section{CONCLUSIONS}

In this study, we provided three new epidemiological parameters, related to the effectiveness of controlling a highly contagious disease, as well as a method for calculating these parameters. These data were determined for 92 different countries, states and provinces. Comparing effectiveness data of countries with and without lockdown revealed that there was no statistically significant difference in the effectiveness between lockdown and 'relaxed' measures. Furthermore, there was also no statistically significant difference in the mortality during the effective phase between lockdown and 'relaxed' measures. These results do not provide any evidence that, on average, lockdown measures are more efficient and that the number of casualties per population is less.

The implications of this study are that there is neither guarantee for lockdown measures being successful, nor certainty that relaxed measures lead to failure. The advantage of relaxed control measures is that they are economy-friendly and prevent associated effects on mental health such as 'lockdown fatigue'. Instead of (late) lockdown measures, any control measures should start very early, accompanied by improving the compliance of citizens through thorough education in epidemiologically necessary changes (i.e. behavioural and others), and appealing to the solidarity and morality of the people.

\section{LIST OF ABBREVIATIONS}

WHO: World health organization

COVID-19: Coronavirus disease

SARS-CoV-2: severe acute respiratory syndrome coronavirus 2

SI: serial intervall

RI: randomness index

$\mathbf{R}:$ reproductive number

$\mathbf{R}^{2}$ : coefficient of determination 
Ethics approval and consent to participate

Not applicable

\section{Consent for publication}

Not applicable

\section{Availability of data and materials}

All data analysed during this study are available from various web sources (see Reference [1] for web links) whose data are completely open. All data generated during this study are included in this published article.

\section{Competing interests}

The authors declare that they have no competing interests

\section{Funding}

The authors did not receive any funding for this research

\section{Authors' contributions}

All authors made substantial contributions to the conception and design of the study as well as to data acquisition, analysis, and interpretations. All authors read and approved the final manuscript.

\section{Acknowledgements}

Not applicable

\section{REFERENCES}

1 COVID-19 Databases: a) COVID-19 pandemic by country and territory. (https://en.wikipedia.org/wiki/COVID-19_pandemic_by_country_and_territory); b) Our World in Data (https://ourworldindata.org/grapher/total-cases-covid-19); c) The COVID tracking project (https://covidtracking.com/data/download);

Worldometer (https://www.worldometers.info/coronavirus/\#countries)

2 WHO. WHO Director-General's opening remarks at the media briefing on COVID-19. 11 March 2020. World Health Organisation, Geneva, Switzerland. Available: https://www.who.int/dg/speeches/detail/who-director-general-s-opening-remarks-at-the-mediabriefing-on-covid-19---11-march-2020; accessed 01/07/2020.

3 Paterlini M. Q\&A: Sweden’s coronavirus strategist. Nature 2002; 580: 574.

4 Holden R, Preston B. The costs of the shutdown are overestimated - they're outweighed by its $\$ 1$ trillion benefit. The Conversation 2020; available: https://theconversation.com/the-costs-of-the- 
shutdown-are-overestimated-theyre-outweighed-by-its-1-trillion-benefit-138303.

Accessed 26/05/2020.

5 Fang Y, Nie Y, Penny M. Transmission dynamics of the COVID - 19 outbreak and effectiveness of government interventions: A data - driven analysis. J Med Virol. 2020; 92:645-659. DOI: 10.1002/jmv. 25750

6 Wang $\mathrm{K}$, Zhao $\mathrm{S}, \mathrm{Li} \mathrm{H}$, et al. Real-time estimation of the reproduction number of the novel coronavirus disease (COVID-19) in China in 2020 based on incidence data. Ann Transl Med 2020; 8(11):689. doi: 10.21037/atm-20-1944

7 Kucharski AJ, Klepac P, Conlan AJK, et al. Effectiveness of isolation, testing, contact tracing, and physical distancing on reducing transmission of SARS-CoV-2 in different settings: a mathematical modelling study. Lancet Infect Dis 2020, Published Online, June 16, 2020 DOI: 10.1016/S14733099(20)30457-6

8 Tang B, Xia F, Tang S, et al. The effectiveness of quarantine and isolation determine the trend of the COVID-19 epidemics in the final phase of the current outbreak in China. International Journal of Infectious Diseases 2020; 95:288-293

9 Amer F, Hammoud S, Farran B, Boncz I, Endrei D. Assessment of Countries' Preparedness and Lockdown Effectiveness in Confronting COVID-19. Disaster Medicine and Public Health Preparedness 2020 Published Online , DOI: https://doi.org/10.1017/dmp.2020.217

10 Leung K, Wu JT, Liu D, Leung GM First-wave COVID-19 transmissibility and severity in China outside Hubei after control measures, and second-wave scenario planning: a modelling impact assessment. Lancet 2020; 395(10233):1382-93. doi: 10.1016/S0140-6736(20)30746-7.

11 Jagodnik KM, Ray F, Giorgi FM, Lachmann A 2020 Correcting under-reported COVID-19 case

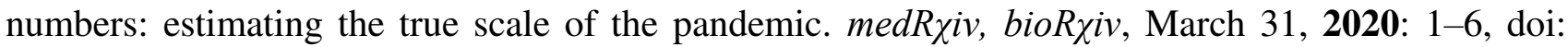
$10.1101 / 2020.03 .14 .20036178$.

12 Maciejewski M 2020 Fixing Covid-19 case number and death toll underreporting. Available: https://towardsdatascience.com/fixing-covid-19-case-number-and-death-toll-underreportingbd9422c88cc4; retrieved 01/07/2020.

13 Ganyani T, Kremer C, Chen D, Torneri A, Faes C, Wallinga J, Hens N 2020 Estimating the generation interval for coronavirus disease (COVID-19) based on symptom onset data. Eurosurveillance 2020; 25(17): 2000257, doi: 10.2807/1560-7917.ES.2020.25.17.2000257

14 Li Q, Guan X, Wu P, et al. Early transmission dynamics in Wuhan, China, of novel coronavirusinfected pneumonia. N Engl J Med. 2020; 382:1199-1207, doi:10.1056/NEJMoa2001316

15 Lipsitch M, Cohen T, Cooper B, et al. Transmission dynamics and control of severe acute respiratory syndrome. Science 2003; 300(5627):1966-1970. doi:10.1126/science.1086616 
16 Cori A., Ferguson N. M., Fraser C., and Cauchemez S. A New Framework and Software to Estimate Time-Varying Reproduction Numbers During Epidemics. American Journal of Epidemiology 2013; 178(9):1505-1512, DOI: 10.1093/aje/kwt133

17 Diekmann O, Heesterbeek H, Britton T. Mathematical tools for understanding infectious disease dynamics. Princeton University Press, Princeton, 2013.

18 Breban R, Vardavas R, Blower S. Theory versus Data: How to Calculate R0? PLoS ONE 2007; 2(3): e282. doi:10.1371/journal.pone.0000282

19 Alfano V, Ercolano S The Efficacy of Lockdown Against COVID-19: A Cross-Country Panel Analysis. Applied Health Economics and Health Policy 2020; 18:509-517 DOI: 10.1007/s40258020-00596-3

20 Viboud C, Simonsen L, Chowell G. A generalized-growth model to characterize the early ascending phase of infectious disease outbreaks. Epidemics 2016; 15: 27-37. DOI: 10.1016/j.epidem.2016.01.002

21 Revicki DA, Frank L. Pharmacoeconomic evaluation in the real world. Effectiveness versus efficacy studies. Pharmacoeconomics 1999; 15:423-434

22 Singal AG, Higgins PDR, Waljee AK. A Primer on Effectiveness and Efficacy Trials. Clinical and Translational Gastroenterology 2014; 5:e45; doi:10.1038/ctg.2013.13

23 Fuss FK, Weizman Y, Tan AM 2020 Similarities and differences between randomness and scaling properties such as fractal dimensions and Hurst exponent in distributed signals. Submitted / in review.

24 COVID-19 Control Measures: a) COVID-19 pandemic by country and territory. (https://en.wikipedia.org/wiki/COVID-19_pandemic_by_country_and_territory); b) Lockdown. (https://en.wikipedia.org/wiki/Lockdown); c) COVID-19 Pandemic Lockdowns (https://en.wikipedia.org/wiki/COVID-19_pandemic_lockdowns; retrieved 03/06/2020); d) COVID19 Pandemic Curfews (https://en.wikipedia.org/wiki/Template:COVID-19_pandemic_curfews; retrieved 03/06/2020); e) ACAPS (acaps.org/covid19-government-measures-dataset).

25 State of Florida, Office of the Governor, Executive Order Number 20/91, April 1, 2020; available: https://web.archive.org/web/20200402024354/https://s33330.pcdn.co/wpcontent/uploads/2020/04/EO-20-91.pdf; accessed 07/07/2020.

26 McGrath RE, Meyer GJ. When Effect Sizes Disagree: The Case of r and d. Psychological Methods 2006; 11(4):386-401.

27 MacIntyre CR. Case isolation, contact tracing, and physical distancing are pillars of COVID-19 pandemic control, not optional choices. Lancet Infect Dis 2020, available: https://doi.org/10.1016/S1473-3099(20)30512-0; https://www.thelancet.com/action/showPdf?pii=S1473-3099\%2820\%2930512-0; accessed 05/07/2020. 
28 Chu DK, Akl EA, Duda S, et al. Physical distancing, face masks, and eye protection to prevent person-to-person transmission of SARS-CoV-2 and COVID-19: a systematic review and metaanalysis. Lancet 2020. https://doi.org/10.1016/S0140-6736(20)31142-9.

29 Cheng KK, Lam TH, Leung CC 2020 Wearing face masks in the community during the COVID-19 pandemic: altruism and solidarity. Lancet 2020, Published Online, available: https://www.thelancet.com/action/showPdf?pii=S0140-6736\%2820\%2930918-1; $\quad$ accessed 05/07/2020.

30 Murphy K, Williamson H, Sargeant E, McCarthy M 2020 Morals, duty or risk?: Examining predictors of compliance with COVID-19 social distancing restrictions. submitted manuscript 2020; available:

https://www.researchgate.net/publication/341638809_Morals_duty_or_risk_Examining_predictors_o f_compliance_with_COVID-

19_social_distancing_restrictions?channel=doi\&linkId=5ecc7bb4458515626ccc60e0\&showFulltext $=$ true; accessed 05/07/2020.

31 Drake TM, Docherty AB, Weiser TG, Yule S, Sheikh A, M Harrison EM. The effects of physical distancing on population mobility during the COVID-19 pandemic in the UK. Lancet 2020; https://www.thelancet.com/action/showPdf?pii=S2589-7500\%2820\%2930134-5; $\quad$ accessed $05 / 07 / 2020$

32 Murphy, K. Enforcing tax compliance: To punish or persuade? Economic Analysis and Policy, 2008; 38(1):113-135.

33 The Guardian 2020 Leading by example: world leaders wearing face masks - in pictures. Available: https://www.theguardian.com/world/gallery/2020/may/28/world-leaders-wearing-face-masks-inpictures-coronavirus; accessed 06/07/2020. 
Figures

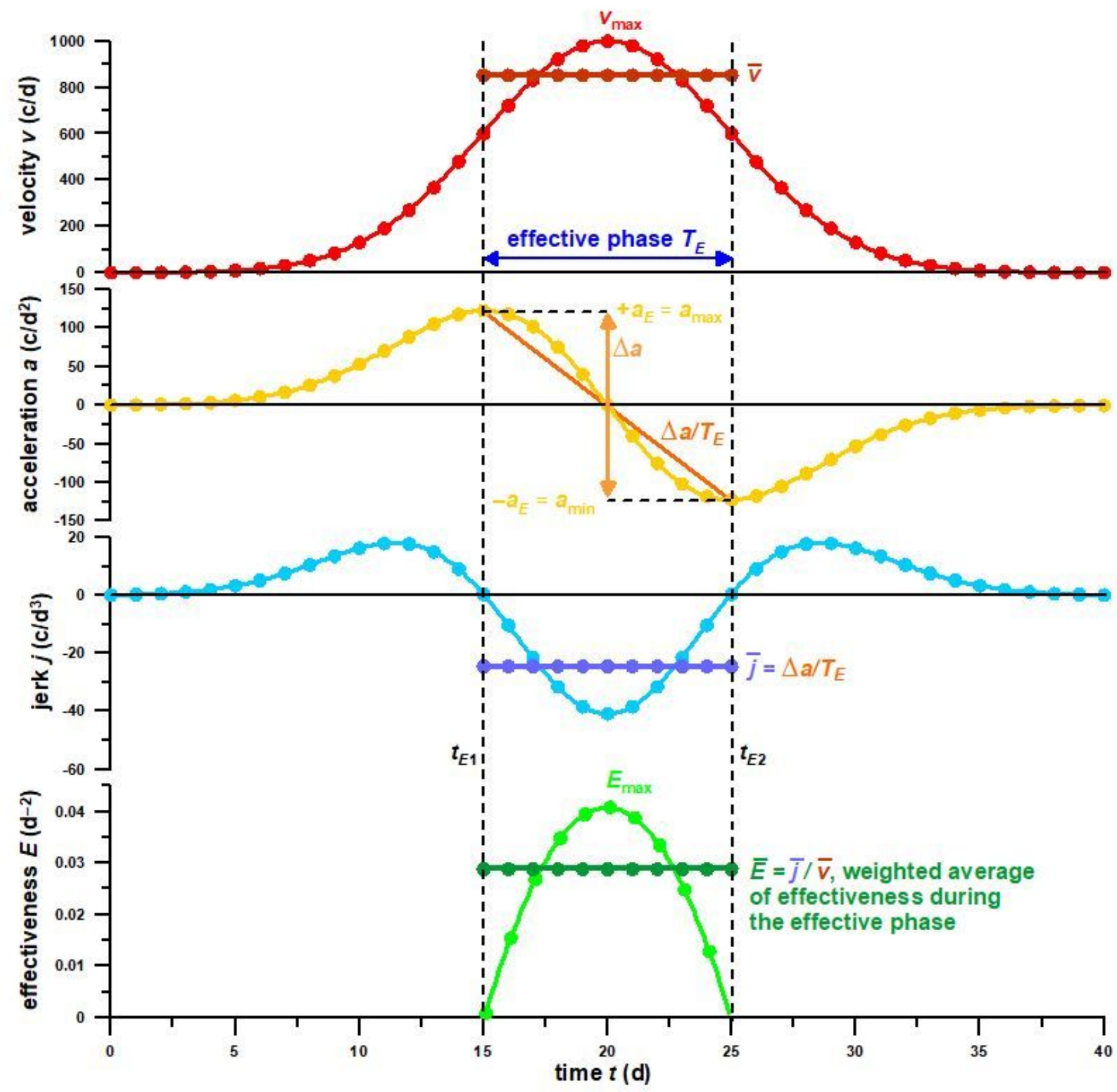

Figure 1

"See the Supplemental Files section for the complete figure caption". 

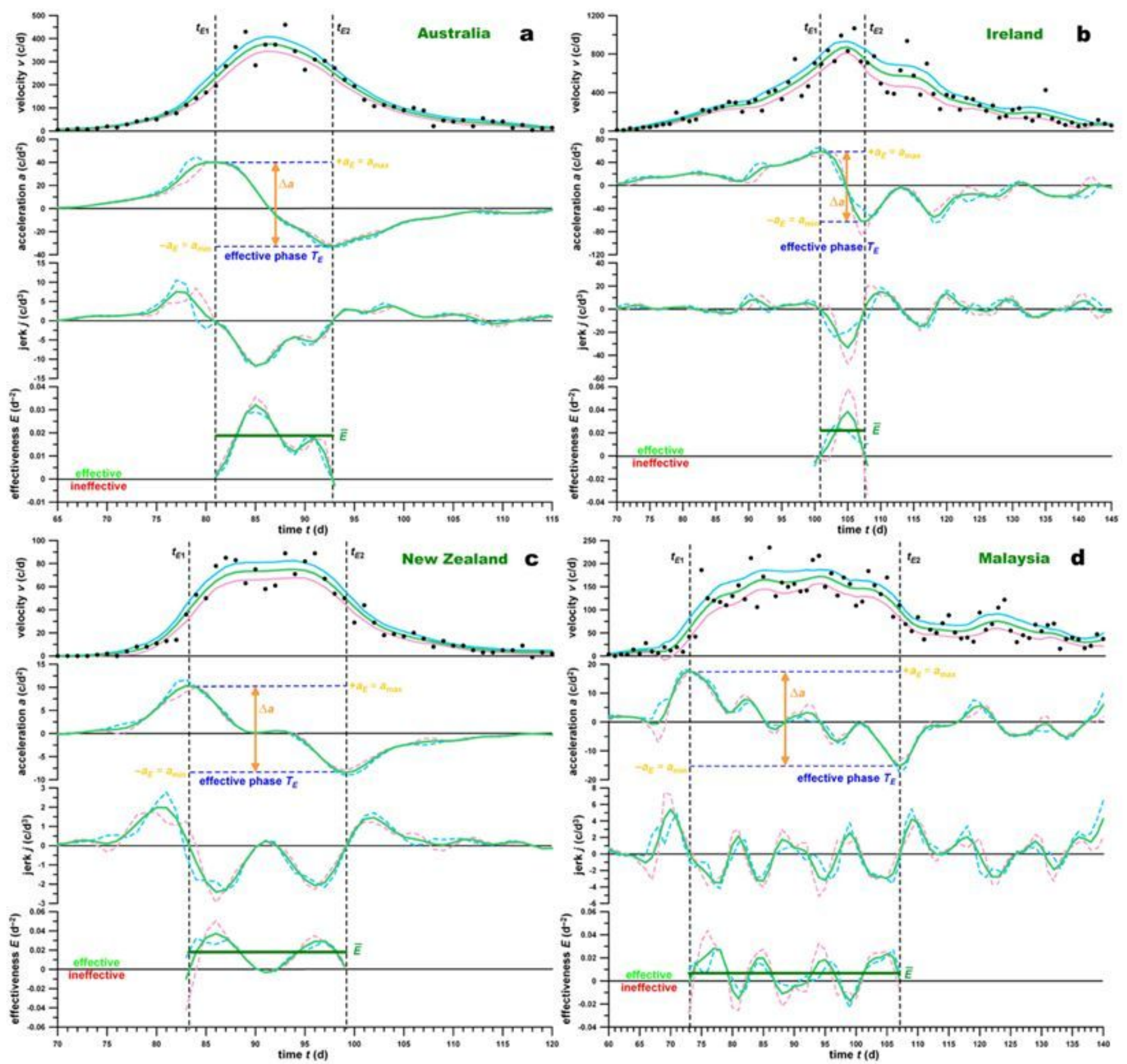

Figure 2

"See the Supplemental Files section for the complete figure caption". 

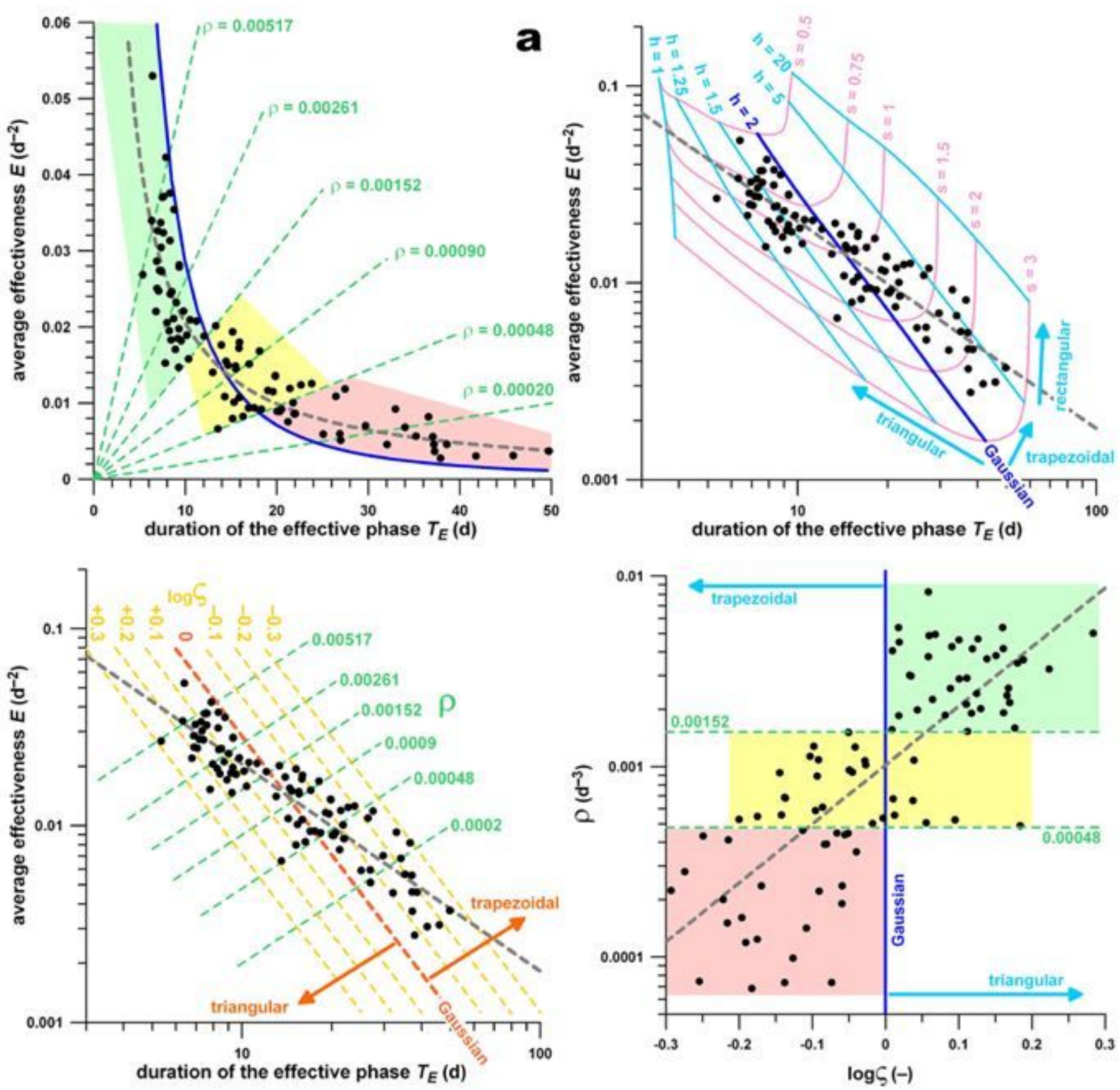

Figure 3

"See the Supplemental Files section for the complete figure caption". 

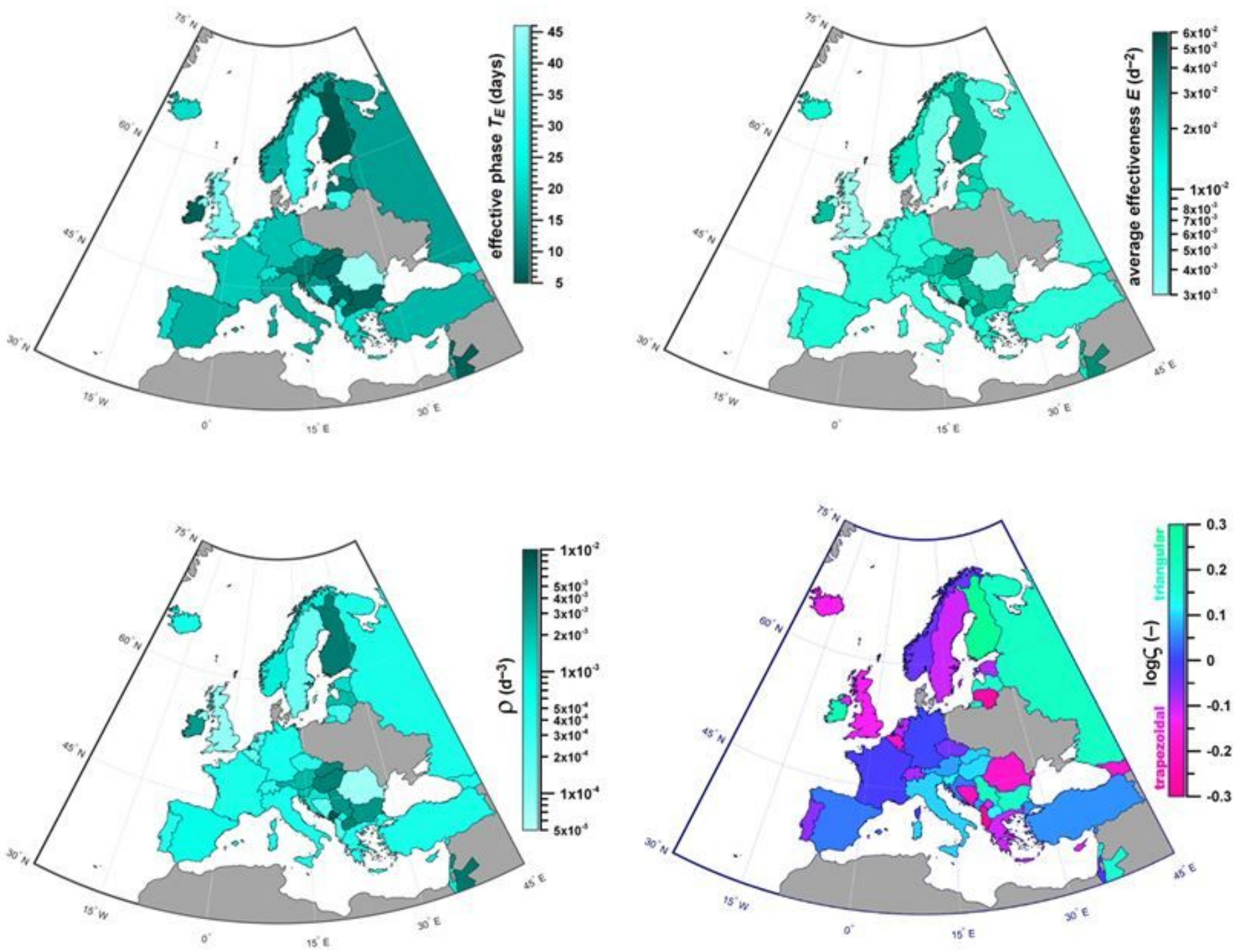

Figure 4

"See the Supplemental Files section for the complete figure caption". 

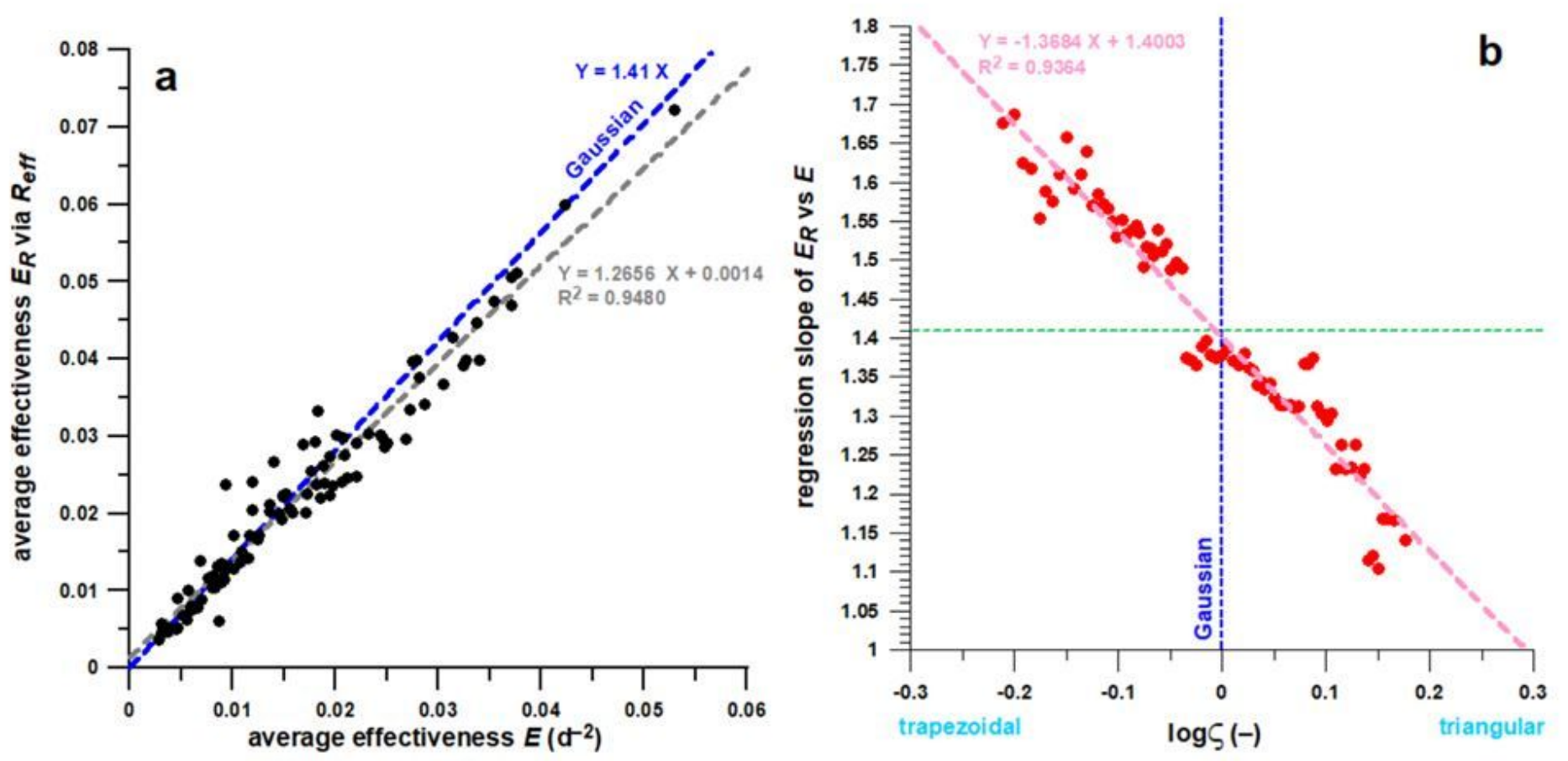

Figure 5

"See the Supplemental Files section for the complete figure caption". 

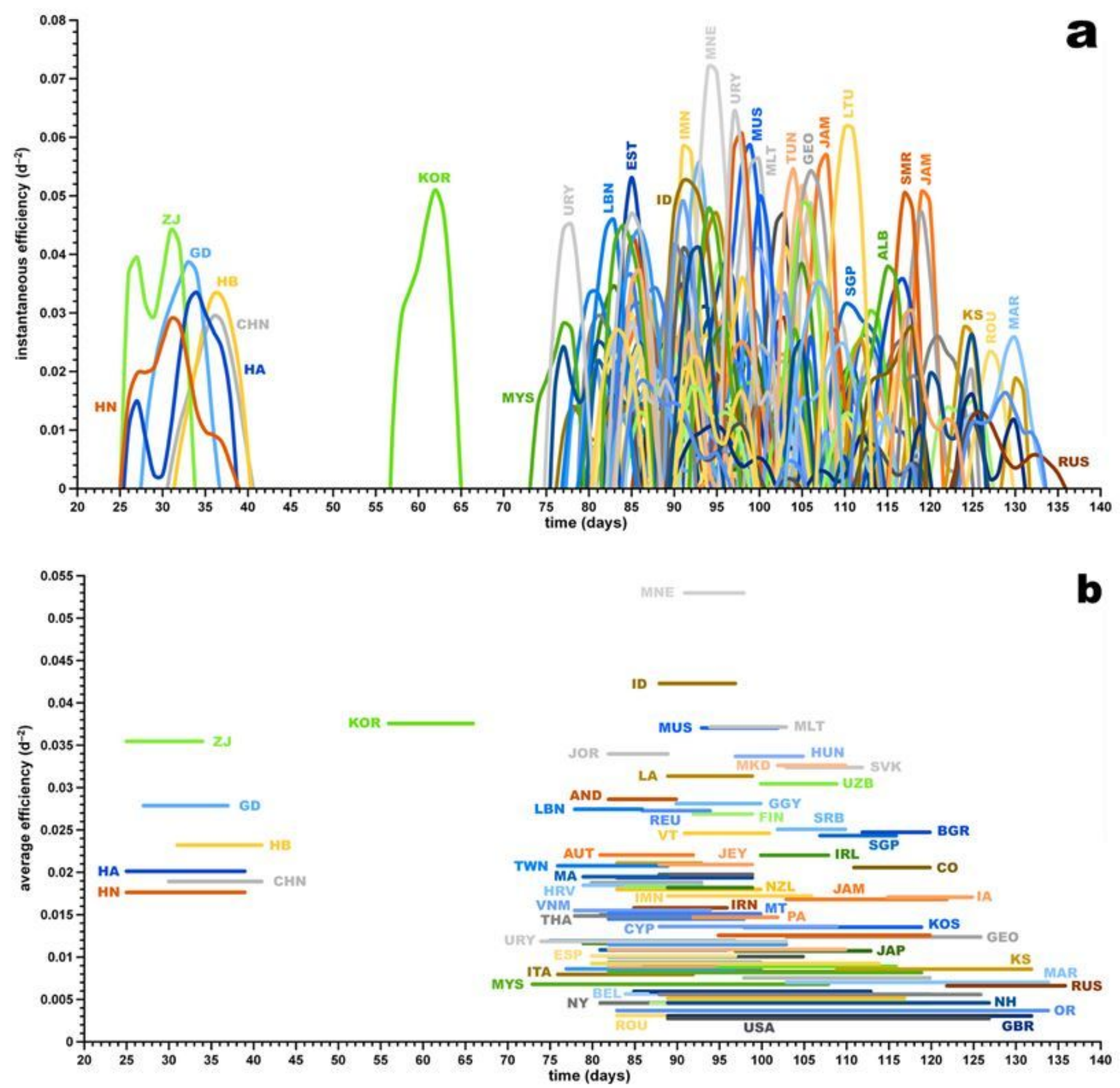

Figure 6

"See the Supplemental Files section for the complete figure caption". 

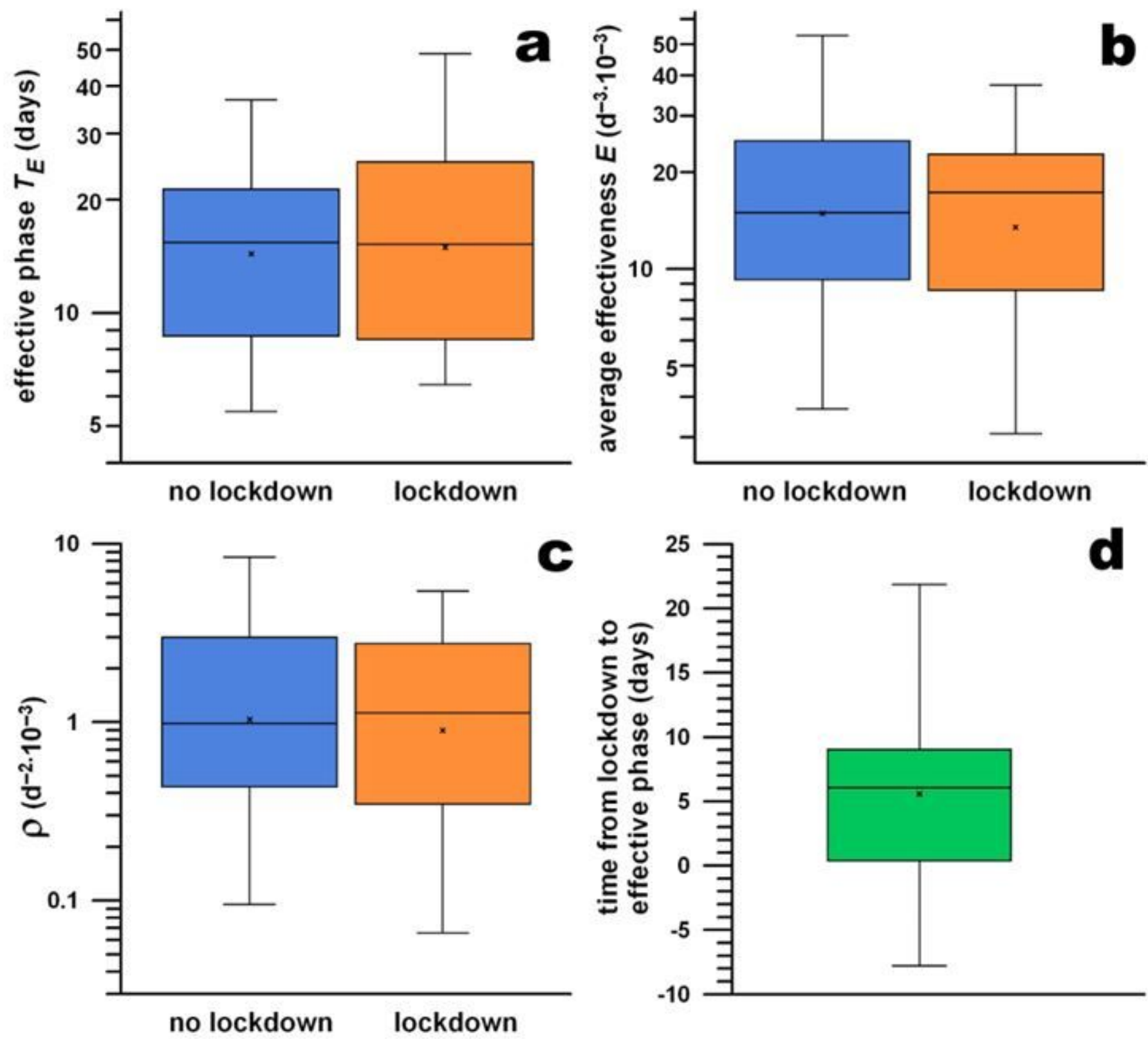

Figure 7

"See the Supplemental Files section for the complete figure caption".

\section{Supplementary Files}

This is a list of supplementary files associated with this preprint. Click to download.

- FigureCaption.docx 